\title{
Combined SMAP-SMOS thin sea ice thickness retrieval
}

\author{
Cătălin Paţilea $^{1}$, Georg Heygster ${ }^{1}$, Marcus Huntemann ${ }^{2,1}$, and Gunnar Spreen ${ }^{1}$ \\ ${ }^{1}$ Institute of Environmental Physics, University of Bremen, Bremen, Germany \\ ${ }^{2}$ Alfred Wegener Institute, Bremerhaven, Germany
}

Correspondence: Cătălin Paţilea (cpatilea@iup.physik.uni-bremen.de)

Received: 11 August 2017 - Discussion started: 18 October 2017

Revised: 8 December 2018 - Accepted: 22 December 2018 - Published: 28 February 2019

\begin{abstract}
The spaceborne passive microwave sensors Soil Moisture Ocean Salinity (SMOS) and Soil Moisture Active Passive (SMAP) provide brightness temperature data in the $\mathrm{L}$ band $(1.4 \mathrm{GHz})$. At this low frequency the atmosphere is close to transparent and in polar regions the thickness of thin sea ice can be derived. SMOS measurements cover a large incidence angle range, whereas SMAP observes at a fixed $40^{\circ}$ incidence angle. By using brightness temperatures at a fixed incidence angle obtained directly (SMAP), or through interpolation (SMOS), thin sea ice thickness retrieval is more consistent as the incidence angle effects do not have to be taken into account. Here we transfer a retrieval algorithm for the thickness of thin sea ice (up to $50 \mathrm{~cm}$ ) from SMOS data at 40 to $50^{\circ}$ incidence angle to the fixed incidence angle of SMAP. The SMOS brightness temperatures (TBs) at a given incidence angle are estimated using empirical fit functions. SMAP TBs are calibrated to SMOS to provide a merged SMOS-SMAP sea ice thickness product. The new merged SMOS-SMAP thin ice thickness product was improved upon in several ways compared to previous thin ice thickness retrievals. (i) The combined product provides a better temporal and spatial coverage of the polar regions due to the usage of two sensors. (ii) The radio frequency interference (RFI) filtering method was improved, which results in higher data availability over both ocean and sea ice areas. (iii) For the intercalibration between SMOS and SMAP brightness temperatures the root mean square difference (RMSD) was reduced by $30 \%$ relative to a prior attempt. (iv) The algorithm presented here allows also for separate retrieval from any of the two sensors, which makes the ice thickness dataset more resistant against failure of one of the sensors. A new way to estimate the uncertainty of ice thickness retrieval was implemented, which is based on the brightness temperature sensitivities.
\end{abstract}

\section{Introduction}

Sea ice is an important climate parameter (Moritz et al., 2002; Stroeve et al., 2007; Holland et al., 2010) and accurate knowledge of sea ice properties is needed for weather and climate modeling and prediction and for ship routing. The thickness of the ice is one of the parameters that determines the resistance against the deforming forces of wind and ocean currents (Häkkinen, 1987; Yu et al., 2001). Even a thin layer of sea ice inhibits evaporation, reduces heat and gas exchange between ocean and atmosphere and increases the albedo (Maykut, 1978; Perovich et al., 2012). Sea ice also provides a solid surface for snow to deposit on, which further reduces heat exchange and increases albedo (Shokr and Sinha, 2015).

The Soil Moisture Ocean Salinity (SMOS) satellite was launched by ESA in November 2009. It is a synthetic aperture passive microwave radiometer working in the $\mathrm{L}$ band $(1.4 \mathrm{GHz})$. The aperture synthesis requires an array of small antennas which reduce the total weight and size of the satellite. The instrument works in a full polarimetric mode, recording all four Stokes parameters. Its large field of view allows for multi-angular observations organized in approximately $1200 \mathrm{~km} \times 1200 \mathrm{~km}$ snapshots.

SMOS has been developed for retrieving soil moisture (Kerr et al., 2012), by inferring the surface emissivity which is correlated with the moisture content, and sea surface salinity (Zine et al., 2008; Font et al., 2010), whereby the measured brightness temperatures (TBs) are linked with the sea salinity through the dielectric constant of the water in the first few centimeters. Modeling and observations showed that at this frequency the radiation is sensitive to ice thickness (IT) up to $50 \mathrm{~cm}$ (Kaleschke et al., 2010, 2012). The atmosphere has little influence on the radiation in the $\mathrm{L}$ band as both ab- 
sorption and scattering are small (Skou and Hoffman-Bang, 2005). The correlation of ice thickness with emitted radiation together with a small atmospheric contribution make SMOS a candidate for thickness retrieval of thin sea ice. To date, two sea ice thickness (SIT) retrieval algorithms have been developed for SMOS, one using the TB intensity averaged over incidence angles between 0 and $40^{\circ}$ (Tian-Kunze et al., 2014) and one using intensity and polarization difference averaged over incidence angles between 40 and $50^{\circ}$ (Huntemann et al., 2014).

In 2015 the Soil Moisture Active Passive (SMAP) satellite was launched by NASA (Entekhabi et al., 2010, 2014). It carries two sensors on board, an L-band radiometer and a radar which share a rotating $6 \mathrm{~m}$ real aperture antenna reflector. The radar was recording high-resolution ( 1 to $3 \mathrm{~km}$ ) data used for soil moisture sensing, until it failed after 3 months. In contrast to the synthetic aperture observations of SMOS, the real aperture antenna observations of SMAP cover an area of $36 \mathrm{~km} \times 47 \mathrm{~km}$ at a fixed incidence angle of $40^{\circ}$ and results in a swath with an approximate width of $1000 \mathrm{~km}$. The preceding technical details of SMAP were presented in Entekhabi et al. (2014). SMAP also includes on-board detection and filtering of radio frequency interference (RFI) while SMOS does not (Mohammed et al., 2016).

After the launch of SMAP, different approaches were taken to convert data products between the two sensors. A previous approach to convert SMOS to SMAP TBs for usage in soil moisture retrieval and assimilation systems is presented in Lannoy et al. (2015) and involves a quadratic fitting of the SMOS TBs at the SMAP incidence angle and employment of auxiliary data and an empirical atmospheric model to correct for the atmospheric and extraterrestrial contributions, respectively. In contrast, Huntemann et al. (2016) convert SMAP $40^{\circ}$ surface TBs to SMOS top-of-the-atmosphere (TOA) equivalent 40 to $50^{\circ}$ averaged TBs through two linear regressions. A more recent attempt for intercalibrating SMOS and SMAP data, using the resulting TBs for a separate SMAP, but also a combined SIT retrieval, was presented in Schmitt and Kaleschke (2018).

In this article, we present a combined SIT dataset using input from both sensors by calibrating the SMAP TBs to those of SMOS (Sect. 4). As a first step, an intercalibration of the TBs of the two sensors is required due to a possible warm bias in SMOS data (Sect. 2) and due to corrections for galactic noise and sun specular reflection contained in the SMAP but not in the SMOS TB data. In addition, the SIT retrieval from Huntemann et al. (2014) is adapted to the new version 6.20 of the SMOS Level 1C data and it will be used as a reference for all other comparisons (Sect. 3.1). This new retrieval is combined with a fit function for the dependence of horizontal and vertical TBs (from now on referred to as $\mathrm{TB}_{\mathrm{h}}$ and $\mathrm{TB}_{\mathrm{v}}$, respectively) on the incidence angle (Sect. 3.2). The fit function is used for RFI filtering and for SIT retrieval at a fixed incidence angle. The fit is also a step required for the
SMOS and SMAP merged product to combine the observations of the two sensors at a common incidence angle.

\section{SMOS and SMAP data sources}

The MIRAS radiometer on board the SMOS satellite has 69 receivers on three arms measuring radiances at $1.4 \mathrm{GHz}$ (Kerr et al., 2001). One complete set of data from the aperture synthesis process done every $1.2 \mathrm{~s}$ is called a snapshot. For this investigation the SMOS Level 1C (L1C) ocean data gridded on the icosahedron Snyder equal area (ISEA) 4H9 grid (Sahr et al., 2003) are used. The grid spacing is $15 \mathrm{~km}$, while the SMOS footprint size varies with incidence angle from approximately $30 \mathrm{~km} \times 30 \mathrm{~km}$ at nadir to $90 \mathrm{~km} \times 30 \mathrm{~km}$ at $65^{\circ}$ (Font et al., 2010). Over the whole field of view the average resolution is approximately $43 \mathrm{~km}$. The Level $1 \mathrm{C}$ data are provided within $24 \mathrm{~h}$ of acquisition.

In full polarization mode, all four Stokes parameters are measured. Data are recorded in the reference plane of the antenna as $T_{X}, T_{Y}, T_{3}$ and $T_{4}$, and are converted to $\mathrm{TB}_{\mathrm{h}}, \mathrm{TB}_{\mathrm{v}}$, $\mathrm{TB}_{3}$ and $\mathrm{TB}_{4}$ in the Earth surface plane (Zine et al., 2008) using

$\left[\begin{array}{c}T_{X} \\ T_{Y} \\ T_{3} \\ T_{4}\end{array}\right]=\left[\begin{array}{cccc}\cos ^{2}(\alpha) & \sin ^{2}(\alpha) & -\cos (\alpha) \sin (\alpha) & 0 \\ \sin ^{2}(\alpha) & \cos ^{2}(\alpha) & \cos (\alpha) \sin (\alpha) & 0 \\ \sin (2 \alpha) & -\sin (2 \alpha) & \cos (2 \alpha) & 0 \\ 0 & 0 & 0 & 1\end{array}\right]\left[\begin{array}{c}\mathrm{TB}_{\mathrm{h}} \\ \mathrm{TB}_{\mathrm{v}} \\ \mathrm{TB}_{3} \\ \mathrm{~TB}_{4}\end{array}\right]$,

where $\alpha=\alpha_{\mathrm{gr}}+\omega_{\mathrm{F}_{\mathrm{r}}}, \alpha_{\mathrm{gr}}$ is the georotation angle and $\omega_{\mathrm{F}_{\mathrm{r}}}$ is the Faraday rotation angle. Within a snapshot, just one or two of the Stokes parameters are measured at the same time. When only one of the Stokes parameters is measured, all three arms of the sensor record the same polarization. In the case of recording a cross-polarized snapshot, one arm of the sensor records one polarization while the other two record the other polarization (McMullan et al., 2008). Measurements of single polarization $(X X$ or $Y Y)$ and crosspolarization $((X X, X Y)$ or $(Y Y, X Y))$ are done alternatively. In order to obtain the values for $\mathrm{TB}_{\mathrm{h}}$ and $\mathrm{TB}_{\mathrm{v}}$ from the matrix, depending if the current measurement is single polarization or cross-polarization, we have to use one or two adjacent snapshots. The missing values required for the conversion are interpolated from neighboring snapshots within a $2.5 \mathrm{~s}$ range and with a maximum incidence angle difference between the measurements of $0.5^{\circ}$.

The SMOS L1C version 6.20 has been operationally available since 5 May 2015; older acquisitions were also reprocessed. This version adds better RFI flagging and improves the long-term and seasonal stability of the measurements. At the same time it introduces a warm bias in the TBs of approximately $1.4 \mathrm{~K}$ relative to the previous version 5.05 over ocean. The bias over the ocean can be $1 \mathrm{~K}$ too warm with respect to the true values. Over Antarctica and land, the bias is above $2 \mathrm{~K}$, which is closer to modeled and ground-based measurements. The new version also reduces the difference in TB between ascending and descending overflights over 
ocean at low latitudes. At high latitudes such changes were not documented. Before, the difference varied considerably with time and latitude due to thermal variations in the instrument. All of the technical details described above for the new data version are presented in SMOS Calibration team and Expert Support Laboratory Level 1 (2015).

The SMAP satellite is positioned on a quasi-polar sunsynchronous orbit with an ascending Equator crossing time at 18:00, while SMOS has an Equator crossing time at 06:00. SMAP carries a conically scanning radiometer with a fixed incidence angle of $40^{\circ}$, which leads to a narrower swath and decreases the area covered at the pole compared to SMOS. The footprint of a SMAP observation is approximately $36 \mathrm{~km} \times 47 \mathrm{~km}$, resulting in an approximate resolution of $40 \mathrm{~km}$. In this study, the SMAP Level 1B data are used which contains time-ordered ungridded TOA TBs. It is available from 31 March 2015 and is provided with a latency of about $12 \mathrm{~h}$.

SMOS and SMAP observe in a restricted band (1.400$1.427 \mathrm{GHz}$ ) reserved for passive radioastronomical use. Nevertheless, there are surface-based artificial sources causing RFI (Mecklenburg et al., 2012). The image reconstruction process required to obtain the SMOS TBs includes an inverse Fourier transform (Corbella et al., 2004). Therefore, not only the grid cells that contain the RFI source are affected but the whole snapshot can be contaminated, resulting in high or even negative TBs (Oliva et al., 2012). Since in nature TB will not exceed $300 \mathrm{~K}$ over the polar ocean (Kaleschke et al., 2010; Mills and Heygster, 2011; Tian-Kunze et al., 2014), a simple RFI filter is used to eliminate the whole snapshot which contains at least one TB exceeding this threshold. This filter is used in the SIT retrieval algorithm presented in Huntemann et al. (2014). An alternative approach for filtering RFI has been shown in Huntemann and Heygster (2015), for which incidence angle binning is used, resulting in a higher preservation of data and fewer gaps on the grid. In this paper we use a new iterative method based on the removal of data with a high difference relative to the SMOS TBs' fit curve, as presented in Sect. 3.2. Since SMAP contains on-board hardware for detection and filtering of RFI and neighboring pixels are unaffected by an RFI source, no additional filtering is required for the SMAP Level 1B data.

\section{Sea ice thickness retrieval using a fit function}

Due to the new SMOS data version 6.20 used here compared to version 5.05 used in Huntemann et al. (2014), a retraining of the SMOS thin ice thickness retrieval is necessary. First, in Sect. 3.1 we use the method presented in Huntemann et al. (2014), just using the newer data version 6.20. This involves averaging the TBs between 40 and $50^{\circ}$ incidence angle. Secondly, we employ a fitting function using the dependence of TB on incidence angle (Sect. 3.2) as input for the retrieval
(Sect. 3.3). The fitting function is used to obtain SMOS TBs at a fixed incidence angle.

\subsection{SMOS retrieval retraining}

Three SMOS grid cells in the Kara and Barents seas located at $78.71^{\circ} \mathrm{N}, 57.41^{\circ} \mathrm{E}, 77.37^{\circ} \mathrm{N}, 81.71^{\circ} \mathrm{E}$ and $75.81^{\circ} \mathrm{N}$, $79.57^{\circ} \mathrm{E}$ were used for training over a period of 3 months (1 October-26 December 2010), with SIT obtained using the relation with the cumulated freezing degree days (CFDD) based on NCEP temperature data as presented in Huntemann et al. (2014). CFDD is the daily average temperature below $-1.8^{\circ}$ (freezing point of sea water) integrated over time with sub-freezing temperatures (Bilello, 1961). The relation between the CFDD and the thickness as presented in Bilello $(1961)$ is $\operatorname{SIT}(\mathrm{cm})=1.33 \cdot\left(\operatorname{CFDD}\left({ }^{\circ} \mathrm{C}\right)\right)^{0.58}$. The ASI (Spreen et al., 2008) sea ice concentration (SIC) product was used to filter low SIC data during the training period. Only during the early part of the freeze-up when ice is really thin was the SIC allowed to have a value between 0 and $100 \%$ (Huntemann et al., 2014), otherwise $100 \%$ SIC was required. The TBs are averaged daily over the incidence angle range between 40 to $50^{\circ}$. The functions

$$
\begin{aligned}
& I_{a b c}(x) \quad=a-(a-b) \cdot \exp (-x / c), \\
& Q_{a b c d}(x)=(a-b) \cdot \exp \left(-(x / c)^{d}\right)+b
\end{aligned}
$$

are fitted to the intensity $I$ and polarization difference $Q$ data measured over the training areas and the SIT resulting from the CFDD method, where $a, b, c$ and $d$ represent the curves' parameters (Table 1) and $x$ is the SIT, while $I$ and $Q$ are the TB intensity and polarization difference, respectively. The SIT retrieval curve is the result of using the two fitted functions from Eq. (2) in the $(Q, I)$ space. For each pair of $Q$ and $I$ the minimum Euclidean distance to the retrieval curve is used to determine the SIT. The retrieval curve parameters for data version 5.05 presented in Table 1 are updated values of the Huntemann et al. (2014) that are currently used for daily processing at the University of Bremen (https://www.seaice.uni-bremen.de/start/, last access: 21 January 2019).

Figure 1 shows the retrieval curves in the $(Q, I)$ space. The dots on the curves represent the SIT increasing with intensity and decreasing with polarization difference in steps of $10 \mathrm{~cm}$ from 0 to $50 \mathrm{~cm}$. Over $50 \mathrm{~cm}$ the retrieval is too sensitive to small changes in intensity and polarization difference and it will be cut off. The SIT retrieval curve for data version 5.05 and the retrained curve using the 6.20 data version are shown in black and blue, respectively. The new data version exhibits a value $\sim 1.7 \mathrm{~K}$ higher value at zero SIT for intensity and polarization difference. The discrepancy increases up to $3 \mathrm{~K}$ at $50 \mathrm{~cm} \mathrm{SIT.}$

Figure 2a shows the intensity for 29 October 2010 using daily mean TBs for each grid cell. The data have been regridded to the NSIDC polar stereographic grid with a resolution of $12.5 \mathrm{~km}$. This resolution is an oversampling of the true 
Table 1. Sea ice thickness retrieval curve parameters for the original 5.05 data version training and 6.20 training, and the two fit curve parameters for 40 and $45^{\circ}$ incidence angle.

\begin{tabular}{llrrrr}
\hline Retrieval & Parameter & $a(\mathrm{~K})$ & $b(\mathrm{~K})$ & $c(\mathrm{~cm})$ & $d$ \\
\hline \multirow{2}{*}{5.05} & $I_{a b c}$ & 234.1 & 100.2 & 12.7 & - \\
& $Q_{a b c d}$ & 51.0 & 19.4 & 31.8 & 1.65 \\
6.20 & $I_{a b c}$ & 235.7 & 103.0 & 12.7 & - \\
& $Q_{a b c d}$ & 52.7 & 22.3 & 33.2 & 1.60 \\
fit 40 & $I_{a b c}$ & 236.4 & 101.5 & 12.2 & - \\
& $Q_{a b c d}$ & 42.6 & 17.3 & 32.9 & 1.39 \\
fit 45 & $I_{a b c}$ & 235.4 & 103.3 & 12.5 & - \\
& $Q_{a b c d}$ & 54.0 & 22.2 & 33.0 & 1.47 \\
\hline
\end{tabular}

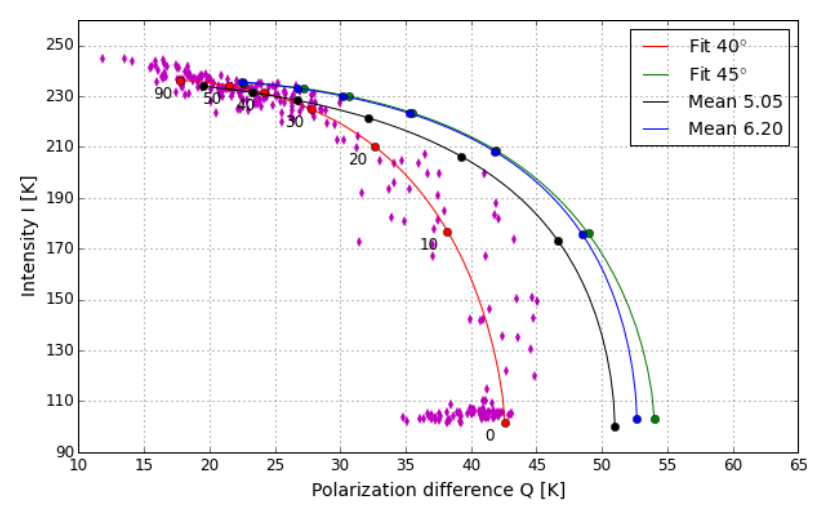

Figure 1. Sea ice thickness retrieval curves derived from SMOS data representing the original algorithm (black), the new data version (blue) and $45^{\circ}$ (green) and $40^{\circ}$ (red) incidence-angle-fitted TBs. Dots represent data from the three training areas used for obtaining the $40^{\circ}$ fit curve. Numbers under the curve represent the SIT in centimeters.

resolution of SMOS, which is $43 \mathrm{~km}$ on average. The original validated retrieval (Huntemann et al., 2014) was trained with the old data version and is used as a reference here. The warm bias of the new version is seen in the difference plot (Fig. 2b), both over ocean area and sea ice. In regions of high contrast like the ice edge or coastlines, both versions tend to produce spillover effects (SMOS Calibration team and Expert Support Laboratory Level 1, 2015). The spillover produces an erroneous increase in TB over ocean areas adjacent to coastlines or the ice edge or a decrease in TB over the sea ice near the ice edge. The erroneous values vary between 1 and 1.5 K (SMOS Calibration team and Expert Support Laboratory Level 1,2015) in the areas mentioned (not visible in the plot). The errors in TB appear due to calibration errors in the SMOS instrument and systematic spacial ripples (Corbella et al., 2015; Martín-Neira et al., 2016; Li et al., 2017) originating from the Fourier reconstruction of the snapshot (Corbella et al., 2005).

The algorithm trained with SMOS data version 5.05 has been compared with the one trained with version 6.20 for the period 1 October to 26 December 2010, considering SIT from 1 to $50 \mathrm{~cm}$. The mean difference of the new retrieval is $-0.22 \mathrm{~cm}$, while the root mean square difference (RMSD) is $1.35 \mathrm{~cm}$. From a total of 5.1 million cumulated data points over the 87-day period and $50 \mathrm{~cm}$ SIT range, $97 \%$ have at most a $3 \mathrm{~cm}$ difference. The mean difference and RMSD are below \pm 1 and $2 \mathrm{~cm}$, respectively, for ice thicknesses below $25 \mathrm{~cm}$. For $50 \mathrm{~cm}$ thickness the mean difference increases to $+4 \mathrm{~cm}$ while the RMSD reaches $11 \mathrm{~cm}$.

A test is done to estimate the error introduced by the use of the original retrieval (Huntemann et al., 2014) with the 6.20 data version. The two algorithms trained with the different data versions only take the 6.20 data as input. The dataset covers the freeze-up period from 1 October to 26 December 2010. The mean difference between the retrained retrieval and the original one is $0.33 \mathrm{~cm}$, with $99 \%$ of the data having a difference of $3 \mathrm{~cm}$ or less, while the RMSD is $0.91 \mathrm{~cm}$. This means that although it is recommended to use the algorithm adapted for the new data version, the difference is below $1 \mathrm{~cm}$ thickness on average for SIT below $51 \mathrm{~cm}$ if processed using the old algorithm.

\subsection{SMOS TBs' fit characteristics}

In the previous section, we have shown that the SIT output with the new data version and new retrieval is consistent with the old data version and retrieval. In all of the next sections the SMOS Level 1C 6.20 version will be used, and when making reference to the original daily mean SIT retrieval, the retrained 6.20 version algorithm from Sect. 3.1 will be used. In each grid cell, the number of data points and the incidence angle range covered are highly variable due to the orbit characteristics, the large incidence angle range of 0 to $65^{\circ}$ and the complex distribution of incidence angle within a SMOS snapshot. Grid cells located closer to the center of the swath will cover a large incidence angle range. Near the swath edges, the range is reduced and low incidence angles are not covered (Font et al., 2010). The snapshots removed using the over $300 \mathrm{~K}$ RFI filter can create a local bias in the average incidence angle. The existence of an RFI source before an observed grid cell, relative to the trackline, will result in the elimination of snapshots with high incidence angle data points for that cell. Conversely, an RFI source located after the grid cell of interest will result in elimination of the low incidence angle data points. The varying angle distribution depending on the position in the swath and the data removal due to the RFI filtering for one grid cell may shift the average incidence angle of the ensemble of observations between 40 and $50^{\circ}$ away from the assumed average of $45^{\circ}$. The average TBs and SIT values retrieved from the affected grid cells will be shifted accordingly. This error can be avoided by fitting a curve to the angular dependent TBs, allowing for a retrieval which uses TBs estimated for a fixed incidence angle.

Here we propose a modified version of the fit functions described in Zhao et al. (2015) as a solution. The fit is applied separately to each polarization, horizontal and vertical, 
(a)

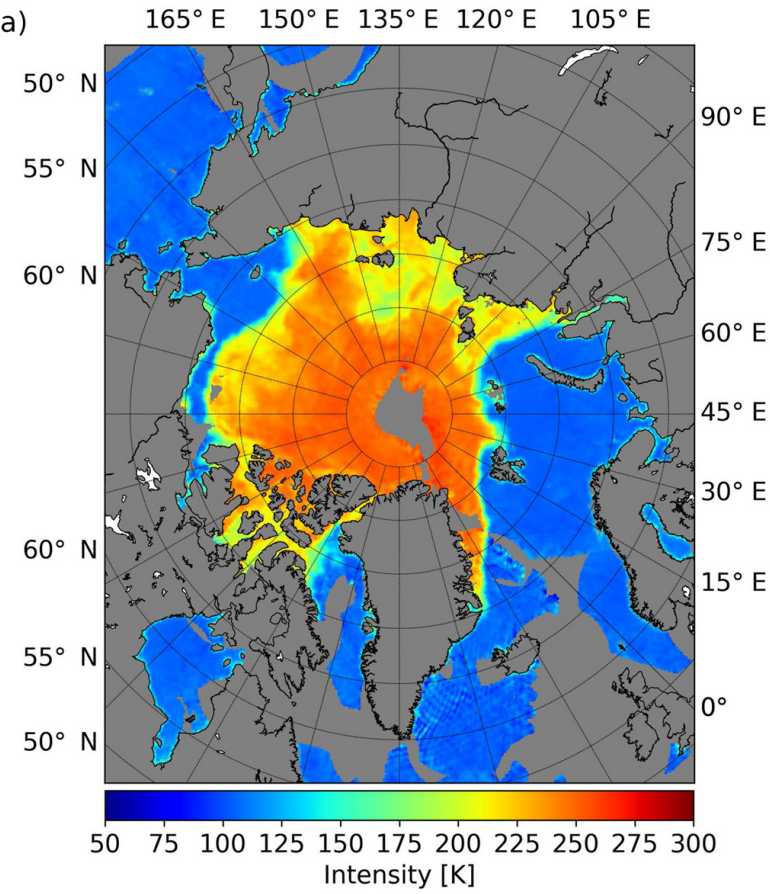

(b)

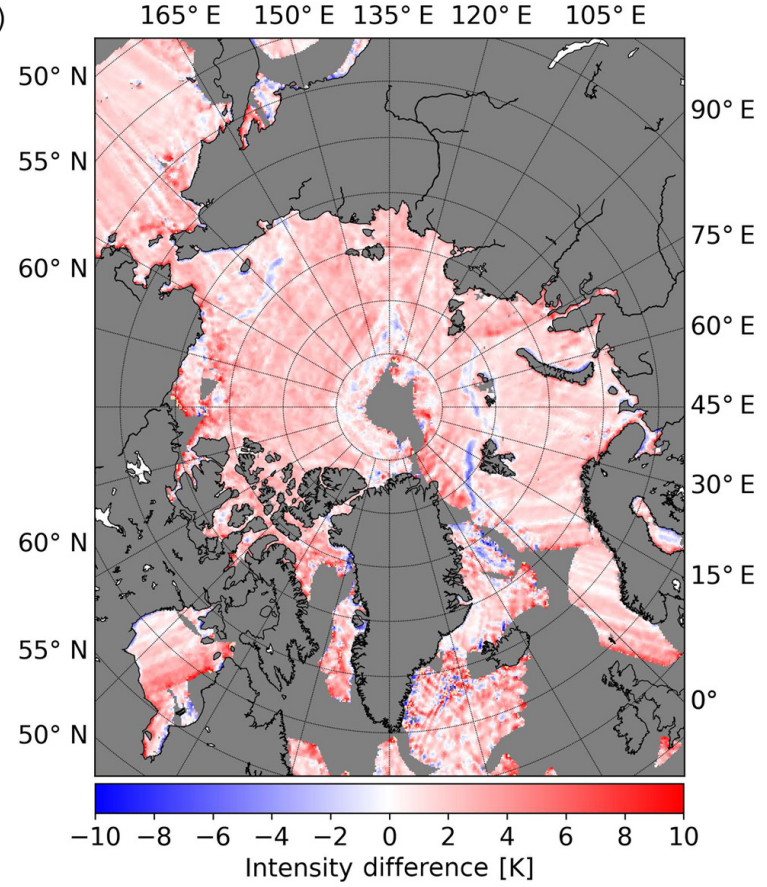

Figure 2. SMOS intensity for data version 6.20 data (a) for 29 October 2010 and intensity difference between the 6.20 and the 5.05 data versions (b).

for each grid cell using daily observations. An initial filtering of RFI is done by removing observations which are flagged in Level 1C data for either being affected by tails of point source RFI or for indicating RFI by the system temperature standard deviation exceeding the expected trend (Indra Sistemas S.A., 2014). The flagged data are removed before the TBs are transformed from the antenna to the earth reference frame.

The fit functions that describe the dependence of $\mathrm{TB}_{\mathrm{h}}$ and $\mathrm{TB}_{\mathrm{v}}$ on the incidence angle are

$$
\begin{aligned}
& \operatorname{TB}_{\mathrm{h}}(\theta)=a_{\mathrm{h}} \cdot \theta^{2}+\frac{C}{2} \cdot\left[b_{\mathrm{h}} \cdot \sin ^{2}(\theta)+\cos ^{2}(\theta)\right] \\
& \operatorname{TB}_{\mathrm{v}}(\theta)=a_{\mathrm{v}} \cdot \theta^{2}+\frac{C}{2} \cdot\left[b_{\mathrm{v}} \cdot \sin ^{2}\left(d_{\mathrm{v}} \cdot \theta\right)+\cos ^{2}\left(d_{\mathrm{v}} \cdot \theta\right)\right],
\end{aligned}
$$

where $\theta$ represents the incidence angle, $C / 2$ is the intensity at nadir and $a_{\mathrm{h}}, b_{\mathrm{h}}, a_{\mathrm{v}}, b_{\mathrm{v}}$ and $d_{\mathrm{v}}$ are five additional parameters used to fit the curves. The Brewster angle effect on the vertically polarized TBs is represented by the additional parameter $d_{\mathrm{v}}$. The fit is done iteratively with a maximum of five steps. For each step the parameter $C$ (Eq. 3) is determined for a given grid cell by first summing up the TBs of horizontal and vertical polarization for each individual observation and then taking the median of the result. The median is used so that any RFI-influenced outliers will not influence $C$. Due to asymmetric change in TB between horizontal and vertical polarization at higher incidence angles, only grid cells with at least one observation under $40^{\circ}$ are considered. This increases the stability of the fit since $C / 2$ represents the inten- sity at nadir. The $40^{\circ}$ threshold is selected due to increased asymmetry between vertical and horizontal TBs at higher incidence angles, which will generate a bias in the computation of the parameter $C$. The other five fit parameters $a_{\mathrm{h}}, b_{\mathrm{h}}, a_{\mathrm{v}}, b_{\mathrm{v}}$ and $d_{\mathrm{v}}$ in the fit functions are determined by a least squares procedure.

In each iteration of the fitting procedure, if the RMSD of the fit is higher than $5 \mathrm{~K}$ or if the RMSD fit difference between successive iterations exceeds $1 \mathrm{~K}, 20 \%$ of the observations with the highest absolute difference from the fit are removed. After the removal of data, in the next iteration the computation of $C$ and the least squares method to fit the parameters is repeated. The data removal in the iterative process is the second step used to discard possible RFI influences.

In the last iteration, if the RMSD of the fit is higher than $5 \mathrm{~K}$ or the RMSD fit difference relative to the fourth iteration is higher than $1 \mathrm{~K}$, the fit parameters will still be used for computation of TBs, at the desired incidence angle, but with a higher RMSD. In the case of non-convergence of the least squares procedure for the fit parameters, the grid cell will be discarded from TB computation.

The fit function is not optimized for extrapolation of the incidence angle range covered. Incidence angles not covered by the observations will have high uncertainty. To avoid extrapolation, only grid cells which contain observations with incidence angles both below and above the desired incidence angle are used for the retrieval; e.g., for a reference angle of $45^{\circ}$, observations below and above $45^{\circ}$ need to be present in the respective grid cell. 
A similar approach for fitting SMOS L1C TBs to a fixed incidence angle using the method presented in Zhao et al. (2015) was done in Schmitt and Kaleschke (2018). For filtering RFI, RFI flags within the SMOS data are used, similar to what is done in this study. As a second step, however, whole snapshots are removed if one data point within the snapshot contains a TB value over $300 \mathrm{~K}$. This was also done previously in Huntemann et al. (2014). For this study, however, we introduced an iterative method to fit the brightness temperatures which does not need a fixed cutoff value for brightness temperature removal anymore. As a result, more data will be removed before the fitting procedure in Schmitt and Kaleschke (2018) compared to the method presented here.

\subsection{Sea ice thickness retrieval training using fitted data}

The retrieval algorithm is retrained as described in Sect. 3.1 but instead of using TBs averaged over $40-50^{\circ}$ incidence angle, we use TBs from the fit process (Sect. 3.2) at a nominal incidence angle of $45^{\circ}$. The resulting retrieval curve (Fig. 1, green) has $1.3 \mathrm{~K}$ higher polarization difference at $0 \mathrm{~cm}$ ice thickness than the algorithm trained with the daily mean data (Fig. 1, blue). The difference decreases to $0.1 \mathrm{~K}$ at $20 \mathrm{~cm}$ thickness and increases to approximately $0.5 \mathrm{~K}$ at $50 \mathrm{~cm}$. This can come from variability in the mean incidence angle. The daily averaged observations have an incidence angle bias of $-0.5^{\circ}$ (with single differences as high as $-2.5^{\circ}$ ) relative to the assumed $45^{\circ}$ one. The smaller incidence angle will result in a smaller $Q$ since this decreases when approaching nadir. The ocean and thin sea ice have low $I$ and a high $Q$. As the sea ice gets thicker, the intensity increases and the polarization difference decreases. For the same incidence angle bias at higher thickness values the $Q$ error will be smaller. The $I$ values for the two curves at the same SIT are nearly the same. The difference between these two curves is small compared to the difference to the SMOS 5.05 data version retrieval curve (Fig. 1, black).

Figure 3 shows the retrieved SIT using the daily mean method (panel a) presented in Sect. 3.1 and the retrained retrieval curve at nominal $45^{\circ}$ incidence angle (panel b) based on the fitted TBs for 29 October 2010. Due to the requirement of the fitting procedure to have observations below $40^{\circ}$ (Sect. 3.2), some grid cells in the central Arctic are not covered anymore. The decrease of the covered area surrounding the North Pole, relative to the old algorithm, is around $1^{\circ}$ in latitude, corresponding to approximately 1000 grid cells. This area is mostly covered by ice with thickness higher than $50 \mathrm{~cm}$, and is thus not the focus of the retrieval. On the other hand for many ocean areas which formerly were excluded by the RFI filtering (grey in Fig. 3a), data are now available, e.g., northeastern Greenland. At the same time in the Hudson Bay area there is a $30 \%$ decrease in the covered surface due to failure of the incidence angle criteria (Sect. 3.2) or the failure of the least squares procedure to converge to a solution. For $90 \%$ of the grid points the difference is less than $3 \mathrm{~cm}$, which is below the estimated retrieval error of $30 \%$ of SIT computed in Huntemann et al. (2014). The daily mean retrieval has a positive mean difference of $0.41 \mathrm{~cm}$. The highest differences appear north of Alaska with values up to $10 \mathrm{~cm}$ (Fig. 3c). This is the result of a biased distribution of the incidence angles, resulting in a large number of grid points having under $45^{\circ}$ mean incidence angle. This decreases the polarization difference dragging the resulting SIT to higher values. Overall the RMSD for this day is $1.9 \mathrm{~cm}$, which is within the expected $30 \%$ error margin of the retrieval.

Figure 4a represents the mean difference (blue) and RMSD (red) of the SIT based on the $45^{\circ}$ incidence-anglefitted TBs relative to the $40-50^{\circ}$ daily mean SIT calculated for the period of 1 October to 26 December 2010. To compute the mean difference and the RMSD we first divide the daily mean SIT into bins of $1 \mathrm{~cm}$ thickness, from 0 to $50 \mathrm{~cm}$. To compute the mean difference for each $1 \mathrm{~cm}$ bin, we select all grid cells with thickness falling within that bin from the daily averaged SIT and subtract the thicknesses of the same grid cells obtained from the fitted TBs. The RMSD is also calculated between the two datasets for each $1 \mathrm{~cm}$ bin. Only grid cells that contain at most $50 \mathrm{~cm}$ are used. Also there must be a nonzero thickness in at least one of the two algorithms so that the high number of open water grid cells in both algorithms will not influence the statistics. Overall the SIT from the fitted TB is smaller than the SIT from the 40$50^{\circ}$ incidence angle mean TB. For ice less than $40 \mathrm{~cm}$ thick the mean difference varies between 0 and $-1 \mathrm{~cm}$ and then increases gradually up to $-5 \mathrm{~cm}$ at $50 \mathrm{~cm}$ SIT. The green curve shows the cumulative histogram for daily mean TB at each SIT. Approximately $52 \%$ of the ice thickness differences are below or equal to $3 \mathrm{~cm}$ in the daily averaged TB SIT. This can be explained by the coarse resolution of about $43 \mathrm{~km}$ of SMOS falsely generating thin sea ice at the ice edge due to TB contamination from either the ocean or the ice pack. In addition coastal areas will also spuriously generate thin sea ice due to spillover effects. Overall we can see that $95 \%$ of all data are below $40 \mathrm{~cm}$, while thickness values corresponding to 40 and $50 \mathrm{~cm}$ are contained in the remaining $5 \%$ of the data so that the region of high mean difference is small. Figure $4 \mathrm{~b}$ shows the daily mean difference (blue) and RMSD (red) of the $45^{\circ}$ fitted TBs' SIT relative to the daily average TB SIT. Over the whole period the mean difference stays between 0 and $-0.6 \mathrm{~cm}$, while the RMSD increases from 1.3 to $2.5 \mathrm{~K}$. The increase in RMSD can be explained by the freeze-up period which contains larger areas with intermediate thicknesses compared to the start and peak freeze-up periods which contain either ocean or over $50 \mathrm{~cm}$ SIT grid cells. The $45^{\circ}$ fitted TBs' SIT overall mean difference for the whole period for all thicknesses is $-0.3 \mathrm{~cm}$ with an RMSD of $2.02 \mathrm{~cm}$. 

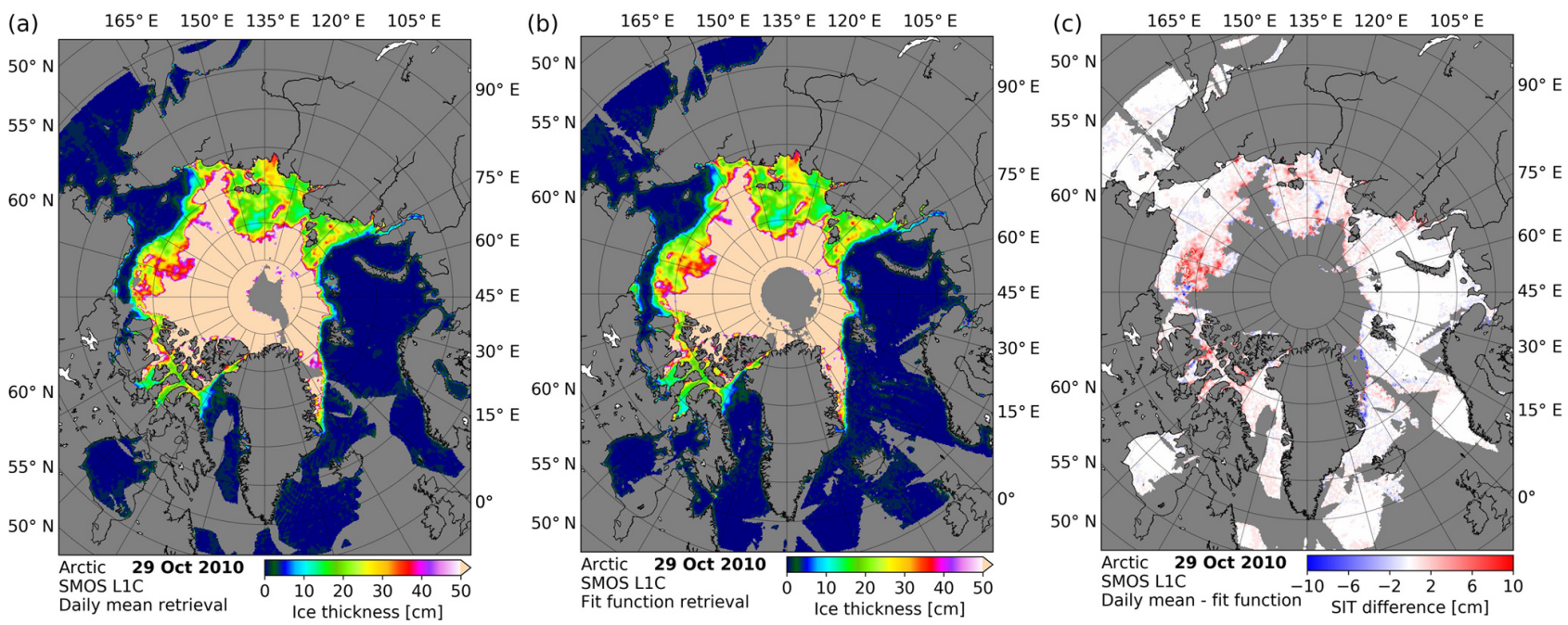

Figure 3. SMOS sea ice thickness retrieved on 29 October 2010 using the 6.20 retrieval (a), the retrieval using $45^{\circ}$ incidence angle fitted TBs (b) and the difference between the two (c) with areas over $50 \mathrm{~cm}$ SIT not shown.

\section{Sea ice thickness retrieval using SMAP data}

This section describes the adaptation of SMOS-based SIT to SMAP TBs. Because SMOS observations have a variable incidence angle, they have to be computed at the fixed incidence angle of SMAP using the fitting function method described in Sect. 3.2. In order to apply SMOS-calibrated SIT retrieval to SMAP, first the TBs of both sensors have to be intercalibrated (Sect. 4.1). In Sect. 4.2 the resulting intercalibrated TBs are mixed and used for generating a combined SMOS-SMAP SIT dataset.

\subsection{SMAP-SMOS intercalibration}

The first step is to retrain the SMOS retrieval as in Sect. 3.3 using the nominal incidence angle of $40^{\circ}$, which is the fixed incidence angle of SMAP. The resulting SIT retrieval curve is shown in red in Fig. 1. As expected, the lower incidence angle results in a lower $Q$, especially for thin ice, and reduces the usable $Q$ range for the retrieval from $22-54$ to $17-43 \mathrm{~K}$. Although the decrease of the dynamic range can increase the sensitivity of the retrieval to small changes in $Q$, the change is nonlinear. At small thicknesses the decrease in dynamic range is large, $11 \mathrm{~K}$ at $0 \mathrm{~cm}$, while the reduction of the dynamic range at $50 \mathrm{~cm}$ is approximately $5 \mathrm{~K}$. The result is that the large change in dynamic range is affecting the low thicknesses which have a low sensitivity to the change of $Q$.

A procedure to convert between SMOS and SMAP TBs over land was previously suggested in Lannoy et al. (2015). It uses a radiative transfer model and auxiliary data to account for atmospheric and galactic contributions for SMOS. For the interpolation of SMOS TBs to $40^{\circ}$ incidence angle it fits a quadratic function to the angle-dependent SMOS TBs.

In this study the procedure to convert from SMAP TBs to SMOS-equivalent TBs is done through simple linear re- gression. For the procedure we use SMOS $40^{\circ}$ measurement data and SMAP L1B TOA observations for the period between 1 October and 31 December 2015, which covers the first freeze-up in the Arctic observed by both sensors. All the data over $55^{\circ} \mathrm{N}$ are considered for intercalibration. In the first step, the SMAP data are gridded daily on the SMOS ISEA 4H9 grid (the native SMOS Level 1C data grid) using a Gaussian resampling with a cutoff distance from the grid cell center of $20 \mathrm{~km}$ and full width half maximum (FWHM) range of $40 \mathrm{~km}$. Only grid cells located more than $100 \mathrm{~km}$ away from the coast are considered to minimize the land contamination. In the second step we determine the fit function parameters for the SMOS data on a daily basis and compute the $40^{\circ}$ SMOS TBs for each grid cell. Figure 5 shows the scatter plots between the TBs of SMAP and SMOS $40^{\circ}$ for horizontal (a) and vertical (b) polarization. For each polarization the magenta line shows the linear regression. We can distinguish two areas of high data point density at the two ends of the open water and thick sea ice clouds, respectively. Over open water at a $\mathrm{TB}$ of 80 and $120 \mathrm{~K}$ for $\mathrm{TB}_{\mathrm{h}}$ and $\mathrm{TB}_{\mathrm{v}}$, respectively, SMOS has a positive mean difference of approximately 3.3 and $5.2 \mathrm{~K}$. At the high TBs representing the solid ice cover, the mean difference for SMOS decreases to 2.7 and $3.3 \mathrm{~K}$ for $\mathrm{TB}_{\mathrm{h}}$ and $\mathrm{TB}_{\mathrm{v}}$, respectively. The bias of SMOS TBs in the 6.20 data version that is presented in Sect. 2 can be one of the sources for the difference between SMOS and SMAP TBs. The asymmetry between low TBs and high TBs can come from the high and low reflectivities of ocean and sea ice, respectively, in the L band. Unlike SMAP, SMOS data do not include correction for galactic noise which can have a higher influence over water due to its high reflectivity. The reflectivity decreases over sea ice, resulting in galactic noise having a smaller impact on recorded values and thus lower differences between corrected and uncorrected TBs. The overall RMSD 

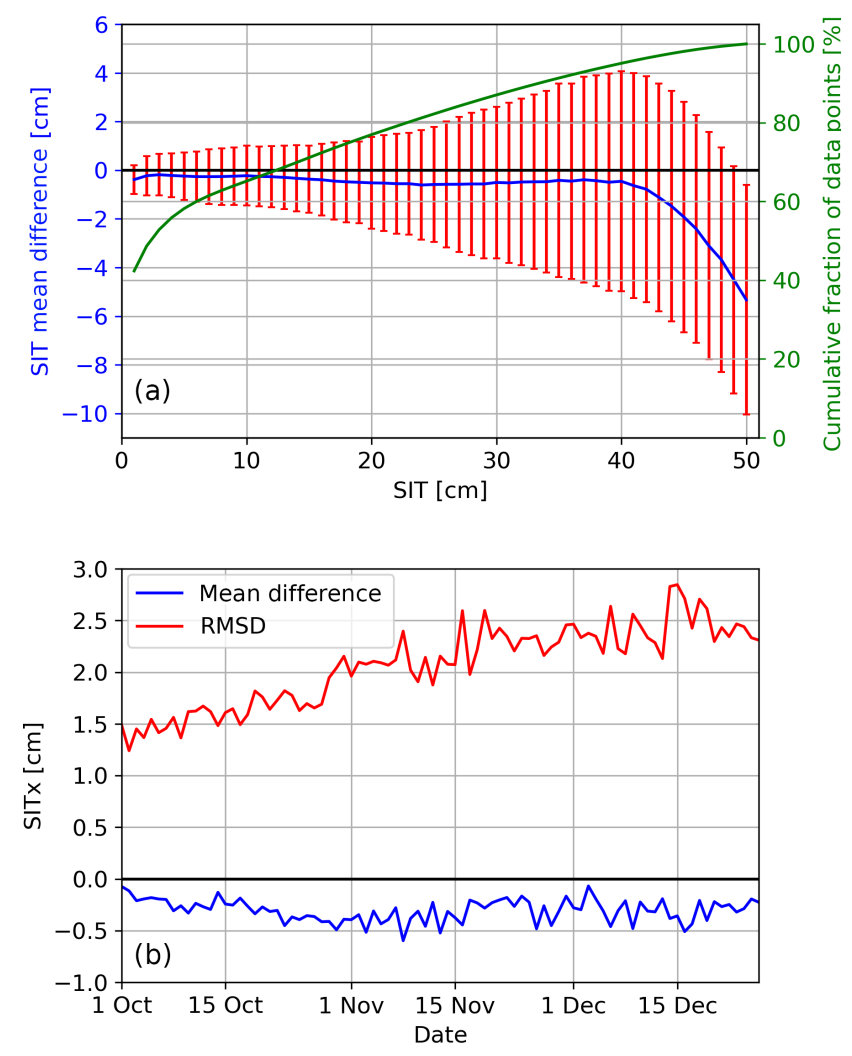

Figure 4. (a) SIT mean difference (blue) calculated by subtracting the SIT computed using $40-50^{\circ}$ daily average from SIT using TBs fitted at $45^{\circ}$ for the 1 October to 26 December 2010 period. The mean difference is computed relative to the daily average SIT in bins of $1 \mathrm{~cm}$ and its corresponding RMSD (red). The green curve represents the fraction from the total amount of data points for each thickness bin. Panel (b) shows the mean difference (blue) and RMSD (red) for each day separately.

of the two linear regressions is 2.7 and $2.81 \mathrm{~K}$ for $\mathrm{TB}_{\mathrm{h}}$ and $\mathrm{TB}_{\mathrm{v}}$, respectively. The resulting linear regression parameters are presented in Table 2.

For this study, in order to use SMAP data for SIT retrieval, we adjust the SMAP TBs by a linear regression to $40^{\circ}$ SMOS incidence angle TBs. A similar calibration of SMAP to SMOS TBs was presented previously in Huntemann et al. (2016). The calibration was done through two separate linear regressions. The SMAP and SMOS $38-42^{\circ}$ incidence angle data were daily averaged and compared to each other for the period 1 October to 31 December 2015 (just as is done here in Sect. 4.1). In the second step, since the SMOS SIT retrieval algorithm used in Huntemann et al. (2016) was developed for $40-50^{\circ}$ daily averaged data, another calibration is required. Using SMOS L1C data for the same period, a linear regression is done between SMOS $40-50^{\circ}$ and SMOS $38-42^{\circ}$ daily averaged data.

There are two main differences between the Huntemann et al. (2016) paper and the current paper. The first difference is that here we use SMAP Level 1 B TOA data, which
Table 2. Parameters for linear regression between SMOS and SMAP TBs.

\begin{tabular}{lrrrr}
\hline Polarization & Slope & Intercept (K) & RMSD (K) & $\mathrm{r}$ \\
\hline$H$ & 0.996 & 3.68 & 2.70 & 0.999 \\
$V$ & 0.985 & 7.03 & 2.81 & 0.997 \\
\hline
\end{tabular}

do not include atmospheric correction, instead of the surface TBs used in Huntemann et al. (2016). This is done to use comparable SMAP data to the SMOS TOA data that are used here. The second difference is that the SIT retrieval has been retrained to the fixed incidence angle of $40^{\circ}$ and it is not necessary anymore to correlate SMAP TBs with the 40$50^{\circ}$ SMOS averaged TBs. Instead we retrain the retrieval to work directly with $40^{\circ}$ SMOS and SMAP TBs. Since the incidence angle difference between the SMAP data and the SMOS $40-50^{\circ}$ data does not need to be corrected anymore, the calibration that is done in the current paper is necessary for (i) compensating for extraterrestrial contributions that are corrected in SMAP TBs and (ii) for the warm bias of the SMOS data. As a consequence, the transition from SMAP to SMOS TBs requires now just one linear regression compared to Huntemann et al. (2016). In this linear regression between the revised SMOS and the SMAP TBs (Sects. 4.1 and 4.2), the RMSD reduced by more than $1.3 \mathrm{~K}$, approximately $30 \%$, compared to Huntemann et al. (2016), indicating a better match of SMOS- and SMAP-based brightness temperature. This, in turn, ensures smaller differences between the retrieved SIT of both instruments and allows the combination of the two retrievals into a joint SIT product.

In Schmitt and Kaleschke (2018) a similar comparison is done to represent the differences between the SMOS and SMAP TB datasets. Compared with the intercalibration done here, 2 years of data are used instead of 3 months, also covering the summer period over the Arctic Ocean. Since we consider that the algorithm presented here is just valid during the winter period, a calibration that covers the summer months is not necessary. The RMSD between the SMOS and adjusted SMAP TBs in Schmitt and Kaleschke (2018) is between 1 and $3 \mathrm{~K}$, which is in the same range of values presented in this paper, i.e., 2.7 and $2.81 \mathrm{~K}$ for $\mathrm{TB}_{\mathrm{h}}$ and $\mathrm{TB}_{\mathrm{v}}$, respectively.

For a daily SIT retrieval, based on horizontal and vertical SMAP TBs, the TBs first are adjusted to the SMOS TB using the linear regression parameters. Then they are gridded into a $12.5 \mathrm{~km}$ resolution polar stereographic grid using a Gaussian weighting for the distance, with a cutoff from the grid cell center of $15 \mathrm{~km}$ and FWHM range of $40 \mathrm{~km}$. For the period from 1 October to 31 December 2015, the difference in SITs between the SMOS $40^{\circ}$ incidence- angle-fitted TB retrieval and the SMAP retrieval is small. Using grid cells containing SIT $\leq 50 \mathrm{~cm}$ and at least one of the two retrievals having SIT $>0 \mathrm{~cm}$, the average difference for the SMOS SIT relative to the SMAP SIT is $-0.2 \mathrm{~cm}$, with a RMSD of $2.39 \mathrm{~cm}$. 

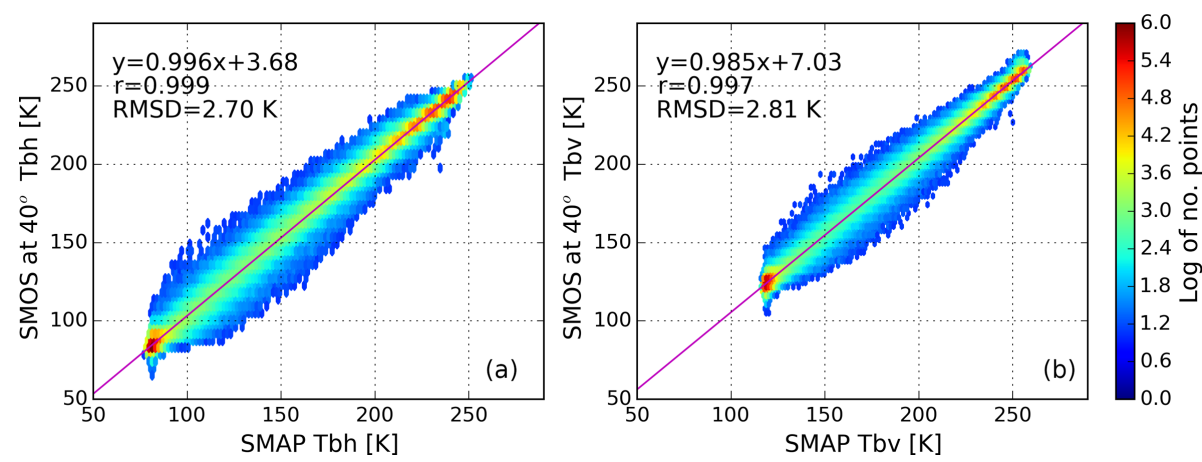

Figure 5. Logarithmic density plot of $\mathrm{TB}_{\mathrm{h}}(\mathbf{a})$ and $\mathrm{TB}_{\mathrm{V}}(\mathbf{b})$ data from SMAP and SMOS for the period 1 October to 31 December 2015. Magenta lines represent the linear regression between the two datasets.

For comparison, the bias and RMSD between SMOS and SMAP SIT found in Schmitt and Kaleschke (2018) are 1 and $7 \mathrm{~cm}$, respectively, which are slightly larger than the results presented here. However, the time period considered in Schmitt and Kaleschke (2018) is different and the SIT retrieval is based on Tian-Kunze et al. (2014); thus it has a different underlying principle.

\subsection{SMOS-SMAP combined sea ice thickness retrieval}

Because of the small differences between the retrievals from the two sensors, combined maps are produced using both of them. The daily mean horizontal and vertical TBs are computed separately for both sensors. For each grid point of the SMOS ISEA 4H9 grid we compute the daily SMOS TBs using the $40^{\circ}$ fit (as in Sect. 3.3). Then the TBs are regridded to the NSIDC $12.5 \mathrm{~km}$ grid commonly used for sea ice maps. SMAP TB data are gridded directly to the NSIDC grid using a Gaussian resampling as was done in Sect. 4.1. The two resulting TB datasets are averaged. Finally the SIT retrieval for the $40^{\circ}$ incidence angle is applied. The result is a SIT map that has the benefit of using data from both sensors (e.g., Fig. 6a) and therefore has greater coverage and is less affected by RFI. For the area north of $55.7^{\circ} \mathrm{N}$ the coverage in the mixed dataset increases by over $6 \%$ compared to the $40-50^{\circ}$ daily mean TB retrieval. Also the combined TBs are more representative for a daily mean due to the $12 \mathrm{~h}$ difference in the Equator crossing time between the two sensors. The RMSD between the original 40 to $50^{\circ}$ incidence angle daily mean retrieval from Sect. 3.1 and the new mixed sensor one is $2.05 \mathrm{~cm}$ for the 1 October to the 31 December 2015 period investigated, while the mean difference is $-0.58 \mathrm{~cm}$. This result means that the mixed sensor SIT is on average smaller than the SMOS daily averaged TB SIT. Figure $6 \mathrm{~b}$ shows the difference between SMOS $40-50^{\circ}$ incidence-angle-averaged TBs' SIT and the mixed data for the 24 October 2015 . The greatest differences appear mostly in the transition area of $40 \mathrm{~cm}$ to over $50 \mathrm{~cm}$. Taking into account just data points with a maximum value of $50 \mathrm{~cm}$ and for at least one of the two datasets a value over $0 \mathrm{~cm}, 93 \%$ of the data have an absolute difference of at most $2 \mathrm{~cm}$ for the 3 months compared. Figure $6 \mathrm{c}$ compares the retrieval done just with the SMOS $40^{\circ}$ fitted TBs to the mixed data one. For this comparison, the average difference is below $-0.1 \mathrm{~cm}$ and the RMSD is $1.37 \mathrm{~cm}$ for the complete 3-month period.

\subsubsection{SMOS-SMAP combined sea ice thickness retrieval algorithm summary}

To reach the final objective of the paper, combining TB data from both SMOS and SMAP sensors for a 1-day SIT retrieval, several steps are required:

- SMOS L1C data are read and converted to the $(H, V)$ reference frame (Sect. 2) and the data are limited to the region covered by the NSIDC polar stereographic grid.

- For each SMOS grid cell the fit parameters for both $H$ and $V$ (Eq. 3) and corresponding uncertainties are derived (Sect. 3.2) and observations not covering the $40^{\circ}$ incidence angle are excluded.

- A landmask is applied.

- TBs at $40^{\circ}$ are derived from the fit parameters (using the procedure from Sect. 3.3 and as applied in Sect. 4.2).

- The resulting TBs and uncertainties are gridded to the NSIDC polar stereographic $12.5 \mathrm{~km}$ grid.

- SMAP L1B data are read and cropped to a minimum latitude of $55^{\circ} \mathrm{N}$.

- TOA TBs of SMAP are gridded to the NSIDC polar stereographic $12.5 \mathrm{~km}$ resolution grid (Sect. 4.1). TB uncertainties are an output of this step (Sect. 5.2)

- The gridded SMAP TBs are converted to SMOSequivalent TBs by linear regression (Sect. 4.1).

- For each NSIDC grid cell the SMOS and the converted SMAP TBs are averaged to obtain the combined TBs (Sect. 4.2). 

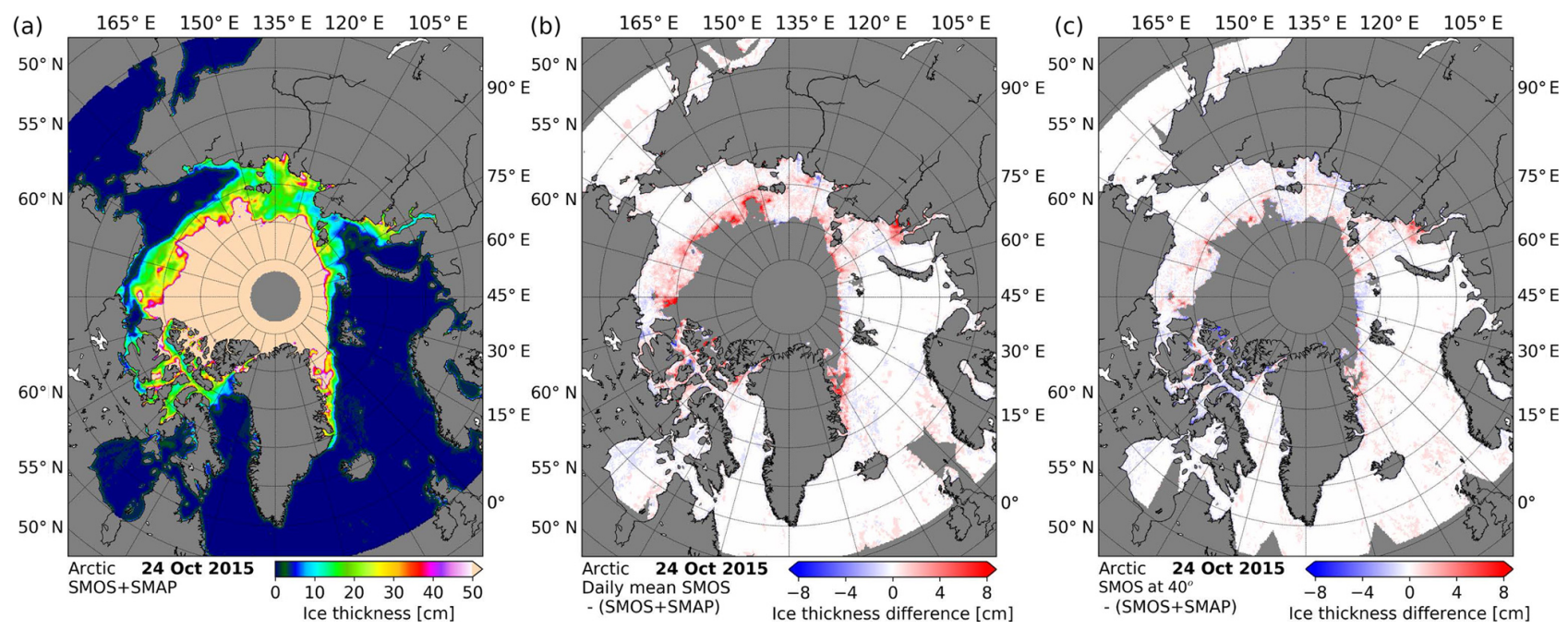

Figure 6. Sea ice thickness retrieved on 24 October 2015 for the joint SMOS-SMAP product (a), the SIT difference between the SMOS daily mean retrieval and the joint retrieval (b) and the SIT difference between SMOS fitted TBs at the $40^{\circ}$ incidence angle and the joint retrieval (c).

- The uncertainties for the combined TB (for each polarization) are computed by error propagation from the uncertainties of $\mathrm{TB}_{\mathrm{h}}$ and $\mathrm{TB}_{\mathrm{v}}$ from SMOS and SMAP (Sect. 5.2).

- The polarization difference $(Q)$ and intensity $(I)$ are calculated from the combined TBs; the associated uncertainties are calculated from the combined $\mathrm{TB}_{\mathrm{h}}$ and $\mathrm{TB}_{\mathrm{v}}$ uncertainties (Sect. 5.2).

- SIT is computed from each $(Q, I)$ pair (Sect. 3.1); the uncertainties associated are computed at the same step using the results of the sensitivity study procedure discussed in Sect. 5.

- Additionally, after the gridding procedure for each sensor, SIT computation is also done separately for both SMOS and SMAP, using the same procedure presented above but using the TBs and uncertainties of the specific sensor instead of the combined ones.

\section{Assessment of uncertainties}

\subsection{Sea ice concentration impact}

The SIT retrieval used in this paper assumes $100 \%$ ice concentration. As a result, the retrieved SIT decreases if this condition is not fulfilled. We assume that TB over sea ice varies linearly with the change in sea ice concentration:

$\mathrm{TB} p(\mathrm{SIT}, \mathrm{IC})=\mathrm{TB} p_{\mathrm{i}}(\mathrm{SIT}) \cdot \mathrm{IC}+\mathrm{TB} p_{\mathrm{w}} \cdot(1-\mathrm{IC})$,

where $p$ represents the polarization, $\mathrm{TB} p_{\mathrm{i}}$ and $\mathrm{TB} p_{\mathrm{w}}$ are the TBs of ice and water, respectively, and IC is the sea ice concentration.
For this study, as a first step, we first use $40^{\circ}$ SMOS TBs from 11 October 2015 for the retrieval. The resulting SIT will be considered the ice thickness (IT) for the assumption that we have a $100 \%$ ice concentration. In the second step we take the same TBs as input for the sea ice $\mathrm{TB} p_{\mathrm{i}}$ and use fixed tie points for $\mathrm{TB} p_{\mathrm{w}}$, with 85 and $125 \mathrm{~K}$ as values for the horizontal and vertical TBs, respectively. For each pair of SMOS TBs used in the first step we consider a range of sea ice concentrations $(15,30,50,70,80$ and $90 \%)$ for which we compute SIT using Eq. (4). The result is an IT value with its corresponding set of six SIC-influenced SITs. As a last step, the IT data points are grouped into bins of $1 \mathrm{~cm}$ thickness. For each $1 \mathrm{~cm}$ bin of IT, we select its corresponding thicknesses from the second step and we averaged them for each SIC separately. Figure 7 shows how the retrieved SIT varies relative to the IT depending on the SIC. For a SIC of $90 \%$ at $10 \mathrm{~cm}$ the retrieved SIT is $8.5 \mathrm{~cm}$, while at $50 \mathrm{~cm}$ it is just $28 \mathrm{~cm}$.

Current retrievals for SIC are influenced by thin sea ice. In Heygster et al. (2014), SIC algorithms have been tested for $100 \%$ sea ice concentration with thicknesses below $50 \mathrm{~cm}$. All algorithms show less than $100 \%$ SIC for thicknesses below $30 \mathrm{~cm}$. In Ivanova et al. (2015) all SIC algorithms registered a decrease in SIC, up to $60 \%$ at $5 \mathrm{~cm}$ and an overall bias of $5 \%$ for over $30 \mathrm{~cm}$. An attempt to retrieve both SIC and SIT at the same time done in Kaleschke et al. (2013) showed a strong increase in noise for the SIT retrieval.

During the winter most of the Arctic is covered by SIC of $90 \%$ and higher (Andersen et al., 2007). For an assumed uncertainty of the sea ice concentration data of $4 \%$ (Ivanova et al., 2015) the error that could be introduced by a correction of SIT for high SIC is higher than that of the error introduced by the assumption of $100 \%$ sea ice concentration 


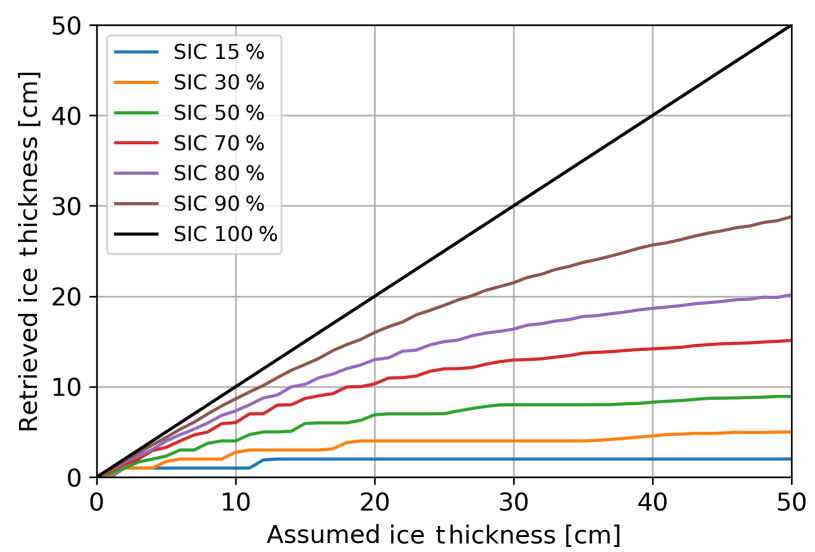

Figure 7. SIT retrieved as a function of the assumed SIT under different SIC values.

(Tian-Kunze et al., 2014). The uncertainty of SIC algorithms at high concentration and their covariation at thin thicknesses will cause high errors if a correction to SIT is applied using current SIC datasets. As a result full ice cover is assumed for the SIT retrieval.

\subsection{Sea ice thickness uncertainties}

In the SIT retrieval using $40^{\circ}$ incidence angle TBs of the two sensors, several factors contribute to the uncertainty: the radiometric accuracy of the observations, RFI contamination in the TB data, the uncertainty in the auxiliary data used for the training of the retrieval, the influence of the SIC on the TBs and the sub-daily variability of the TBs themselves.

Here we propose a method to quantify the uncertainty of the retrieval. We first compute the SIT in the $(Q, I)$ space using the $40^{\circ} \mathrm{TBs}$ trained retrieval (Fig. 8a). The TBs that will be used in a retrieval will more likely be found close to the retrieval curve (Fig. 1, red) but there is variability in the data points, with values going above and below the curve. To also cover the less likely $(Q, I)$ pairs we chose to cover a large range of values for $Q$ and $I$, from 0 to $80 \mathrm{~K}$ and from 80 to $300 \mathrm{~K}$, respectively. The resulting figure follows the training curve pattern, with an $I$ dominating the change in SIT below $20 \mathrm{~cm}$ thickness, while $Q$ becomes more important at higher thicknesses. The SIT over $51 \mathrm{~cm}$ is removed from the figure since we restrict maximum retrieved thicknesses to $50 \mathrm{~cm}$. The $1 \mathrm{~cm}$ thickness over $50 \mathrm{~cm}$ is kept so that we can compute the derivative for $50 \mathrm{~cm}$.

As a second step we compute the derivative as SIT as a function of $Q$ and $I$ seen in Fig. $8 \mathrm{~b}$ and c, respectively. For $Q$ values below the $20 \mathrm{~cm}$ line the change rate is below $0.25 \mathrm{~cm}$ per $\mathrm{K}$ due to the thickness isolines being parallel to the $Q$ axis; thus for the same value of the intensity, a large change in $Q$ will result in a similar thickness value. For thicknesses between 20 and $40 \mathrm{~cm}$ the change increases to $0.5 \mathrm{~cm}$ per K for $Q$ below $60 \mathrm{~K}$, while for thicknesses over $40 \mathrm{~cm}$, the change rate of thickness with $Q$ quickly goes over $1 \mathrm{~cm}$, es- pecially in the area with $Q$ between 20 and $30 \mathrm{~K}$, the range in which most of the data points will fall. A similar pattern also appears for $I$, with the difference that at thicknesses below $20 \mathrm{~cm}$ the change rate of SIT is higher than the one from $Q$ due to the $I$ axis being perpendicular to the SIT isolines. The sensitivity of SIT relative to $Q$ and $I$ will be used to compute the uncertainty of the retrieval. For a given pair $(Q, I)$ and their associated uncertainties we compute the SIT and corresponding SIT uncertainties:

$$
\sigma_{\mathrm{SIT}}=\sqrt{\left(\frac{\partial \mathrm{SIT}}{\partial Q}\right)^{2} \cdot \sigma_{Q}^{2}+\left(\frac{\partial \mathrm{SIT}}{\partial I}\right)^{2} \cdot \sigma_{I}^{2}+2 \cdot\left(\frac{\partial \mathrm{SIT}}{\partial Q}\right)}
$$

where $\sigma_{Q}$ and $\sigma_{I}$ represent the $Q$ and $I$ uncertainties derived through an error propagation method from the errors of $\mathrm{TB}_{\mathrm{h}}$ and $\mathrm{TB}_{\mathrm{v}}$ and $\rho_{Q I}$ is the correlation between the $Q$ and $I$. The values of the SIT derivatives are taken from the second step of the method for each pair of $(Q, I)$.

For this study we do not take into account the radiometric accuracy of either sensor because these errors are small compared to the other errors, especially the TB variation during 1 day. For each SMOS observation at the $40^{\circ}$ incidence angle, the TB uncertainty is assumed to be the RMSD resulting from the fitting process presented in Sect. 3.2. During the fitting routine the RMSD is computed for each iteration and a $5 \mathrm{~K}$ threshold is used for eliminating outliers. Although this process is used to eliminate potential RFI influences in the data, it will also reduce the variability that comes from observations of the same grid cell at different times of the day. For SMAP TBs a weighted standard deviation for each grid cell using all observations from 1 day is used as uncertainty. The weights are applied for each data point that is considered in the calculation of the TB for that grid cell and are computed using

$w_{i}=\exp \left(-\frac{4 \cdot \log 2 \cdot d^{2}}{\mathrm{FWHM}^{2}}\right)$,

where $w_{i}$ is the weight, $d$ is the distance of the SMAP data point location to the center of the grid cell and FWHM is the full width half maximum beamwidth of SMAP, with a value of $40 \mathrm{~km}$. The correlation between the $Q$ and $I$ is -0.68 and -0.66 for SMOS and SMAP, respectively. The correlation was calculated for the period 1 October to $31 \mathrm{De}-$ cember 2015. It was computed for the whole 3 months over the whole Arctic using daily fitted TBs for SMOS and daily Gaussian resampled TBs for SMAP for each grid cell.

Another source of error for the current retrieval is the uncertainty in the training data. For this study we included two parameters that could generate uncertainty in the creation of the retrieval curve and thus in the retrieval itself. The first parameter is the SIC. In the training data, as presented in Huntemann et al. (2014), the SIC is assumed to be $100 \%$, although this cannot be ensured for the whole period covered. 


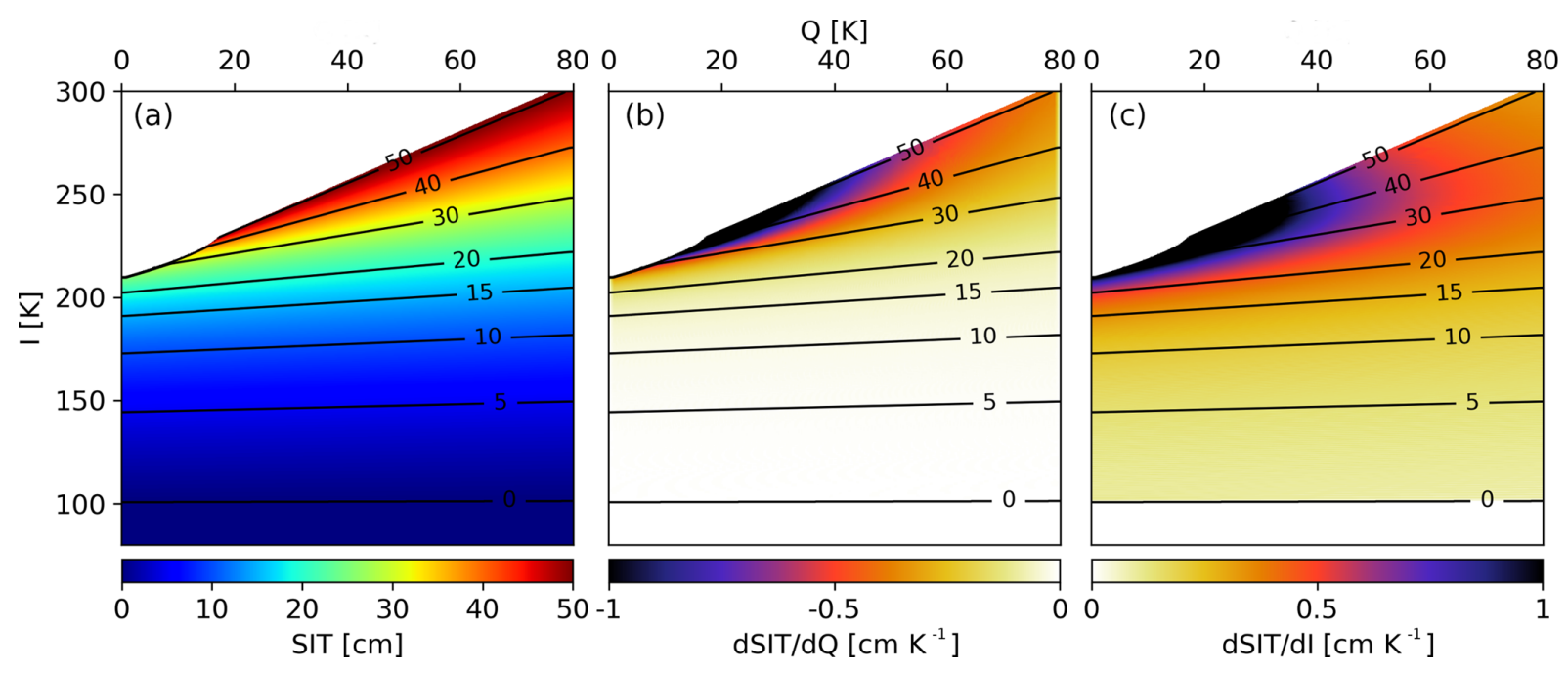

Figure 8. SIT (a) computed with the $40^{\circ} \mathrm{TB}$ algorithm (Fig. 1, red curve) represented in the space of $Q$ and $I$. Derivative of SIT as a function of $Q$ (b) and $I$ (c). The black lines in all three figures represent the isolines of the SIT derived from panel (a).

The initial freeze-up period, during which thin sea ice can covary with SIC (as discussed here in Sect. 5.1), allows SIC between 0 and $100 \%$, while later drops in SIC are removed. To take into account the uncertainty in the SIC data used for the training, we take 1 day of TBs and corresponding SIT data and order them in $1 \mathrm{~cm}$ bins from 0 to $50 \mathrm{~cm}$. Then we vary the SIC taken into account with $\pm 5 \%$ standard deviation and compute the range of ice thicknesses that will be derived from this, i.e., assuming $105 \%$ SIC and $95 \%$ using the linear mixing of open water contribution to TBs as discussed in Sect. 5.1. The result is shown in Fig. 9a. A $5 \%$ variation in the SIC for an assumed $100 \%$ SIC cover, we obtain a polynomial increase in SIT error with increasing SIT, starting from nothing at $0 \mathrm{~cm}$ and reaching approximately $31 \mathrm{~cm}$ at $50 \mathrm{~cm}$.

The second additional parameter used for estimating error in the retrieval curve comes from the CFDD daily variability in the estimation of training ice thickness using the model. While SMOS passes over a training area in the Arctic region, the recorded TBs are representative of that specific time of the over pass. Close to the poles a specific location can be covered multiple time by consecutive overpasses. For the generation of the retrieval curve, connecting the daily average temperature from NCEP with a daily averaged TB localized in time will create a bias between the retrieved thickness and actual SIT. The variation in temperature, with lower temperatures increasing the ice generation rate, and its nonlinearity, with thinner ice growing faster for the same temperature than thicker sea ice, generates an uncertainty in the SIT computed for the retrieval curve. For quantifying this uncertainty we will select a fixed daily temperature of $-25^{\circ} \mathrm{C}$ for which we compute the amount of thickness increase, with $1 \mathrm{~cm}$ thickness as a starting point. This thickness will be considered the uncertainty of the SIT retrieval due to incorrect representation of the total sea ice increase in a day rela- tive to the recorded TBs in the training areas. The result is shown in Fig. 9b. For small thicknesses the error added by the CFDD daily variability is over $5 \mathrm{~cm}$ due to the greater exchange of heat between the ocean and the atmosphere, while it decreases exponentially towards $1 \mathrm{~cm}$ for the higher thicknesses. Also it can be seen that lower temperatures will increase the error due to the greater exchange of heat between the ocean and the atmosphere.

To derive the final uncertainty for SIT, we use a simple error propagation method for the three uncertainty values that we want to include: uncertainty derived from the TBs and the associated retrieval, the uncertainty in the SIC training data and the uncertainty due to CFDD daily variability. Figure 10 shows as an example the scatter plot and moving average (red lines) of the SIT uncertainty (Eq. 5) for 24 October 2015 for SMOS (panel a) and SMAP (panel b). The restrictions imposed on the RMSD of the SMOS data have a clear impact on results. The majority of TB uncertainties for SMOS are over $2 \mathrm{~K}$, and this leads to high uncertainty for higher thicknesses. Because the SMAP data still contain the full daily variability of observations, there will be grid cells with over $5 \mathrm{~K}$ uncertainty, but overall the median is around $1.2 \mathrm{~K}$, in comparison with SMOS for which the uncertainties are clustered around $4 \mathrm{~K}$. Again, the smaller uncertainty of the SMOS data is only due to the TB fitting procedure, which removes outliers. Without that, for the raw data, the SMOS uncertainty would be similar or even larger than for SMAP. The CFDD daily variability uncertainty offers an offset of the SIT uncertainty relative to the zero line until approximately $20 \mathrm{~cm}$. For both sensors we can observe a rapid increase of the uncertainties beyond $20 \mathrm{~cm}$ SIT (Fig. 10), which can be explained by the high impact of SIC and the high sensitivity of the retrieval at values over $30 \mathrm{~cm}$. 

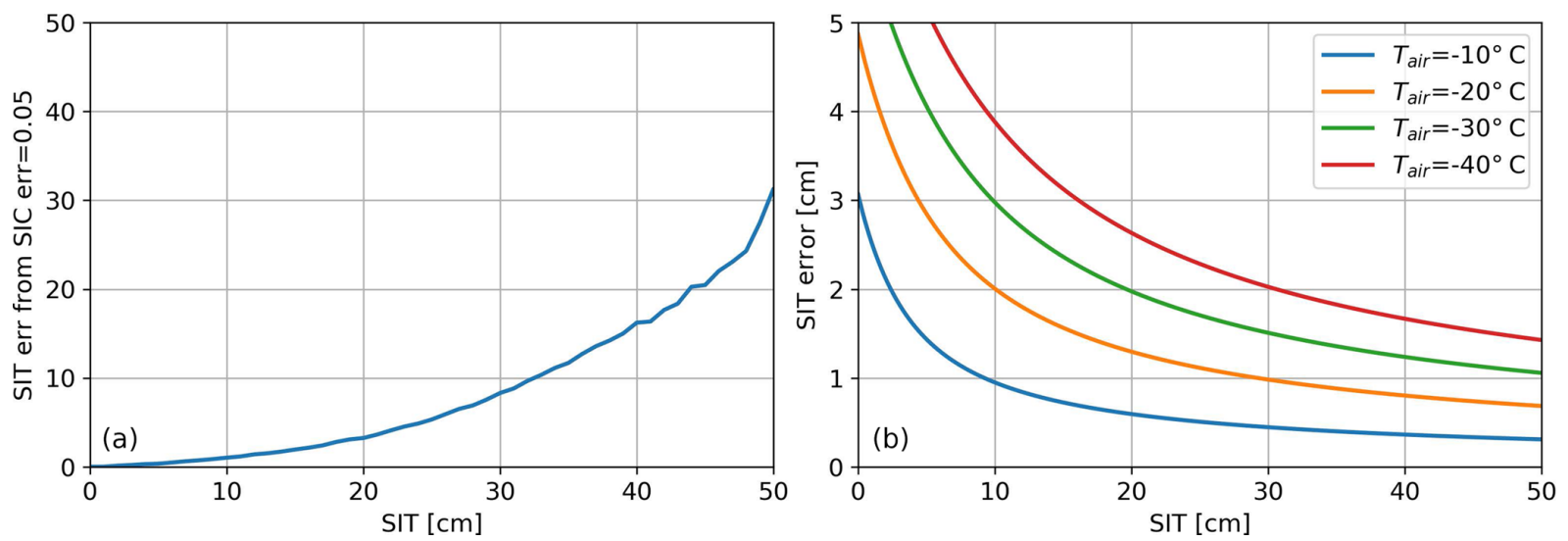

Figure 9. (a) SIT error with change of SIT for a SIC uncertainty of $5 \%$. (b) SIT error as a function of SIT due to CFDD daily variability calculated for various fixed $2 \mathrm{~m}$ air temperatures.
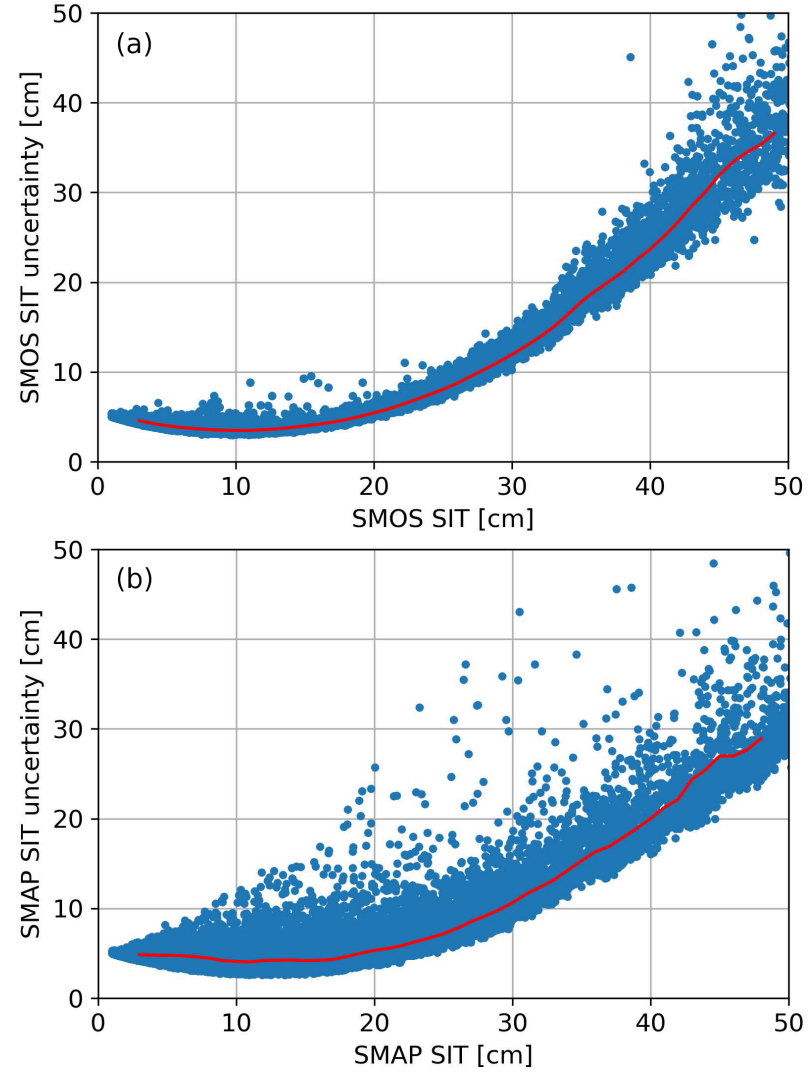

Figure 10. Scatter of SMOS (a) and SMAP (b) retrievals at the $40^{\circ}$ incidence angle for 24 October 2015 in the Arctic and their respective uncertainties. The red line shows the rolling average of the uncertainty.

\section{Comparison to ship-based observations}

Due to the nature of thin sea ice, in situ observations are extremely rare. Thin sea ice usually appears during the initial stages of the freeze-up period. Depending on the surface ra- diative energy fluxes and precipitation, the sea ice growth may vary. From the initial formation of sea ice to $50 \mathrm{~cm}$ thickness it may take less than 1 month. This can leave a short amount of time for in situ observations. In this section we will compare the SIT recorded from the R/V Sikuliaq during the period 5 October to 4 November 2015 in the Beaufort and Chukchi seas with SIT data obtained from our combined SMOS-SMAP product. With more than $75 \%$ of the ship observations being of thin ice below $50 \mathrm{~cm}$ ice thickness, the dataset is well suited for comparison to the SMOSSMAP product presented in this paper. The SIT and SIC data recorded by the ship were mainly obtained by hourly visual ice observations using the ASPeCT protocol (Worby and Ackley, 2000). During the day, this allowed for an estimate of ice thickness in an approximate radius of $1 \mathrm{~km}$, while during the night this just allowed for an estimate of ice thickness in the ship vicinity covered by the floodlights.

We divide the ship data into separate days, and average the ice thicknesses within a $20 \mathrm{~km}$ radius from the center of each $12.5 \mathrm{~km}$ sized NSIDC grid cell. Figure 11 shows the comparison between the SMOS-SMAP product and the shipbased observations, with the color indicating the ice concentration. The estimation of the ice area fraction was done using the ASI ice concentration product from the University of Bremen (https://www.seaice.uni-bremen.de/start/; last access: 21 January 2019; Spreen et al., 2008) resampled to the $12.5 \mathrm{~km}$ grid. The points are well aligned around the oneto-one line, despite a high scatter. We eliminate grid cells which contain thicknesses between 60 and $120 \mathrm{~cm}$ in the ship data. With the remaining data we compute a linear regression of the two datasets, which results in a slope of 0.71 , an RMSD of $6.58 \mathrm{~cm}$ and a correlation coefficient of 0.58 . Thus, SMOS-SMAP slightly overestimates the ice thickness compared to the ship observations. On the other hand, in this comparison, no SMOS-SMAP observations show higher ice thicknesses than $30 \mathrm{~cm}$ which may be caused by the reduced ice concentrations; e.g., for $90 \%$ SIC the retrieved SIT can- 


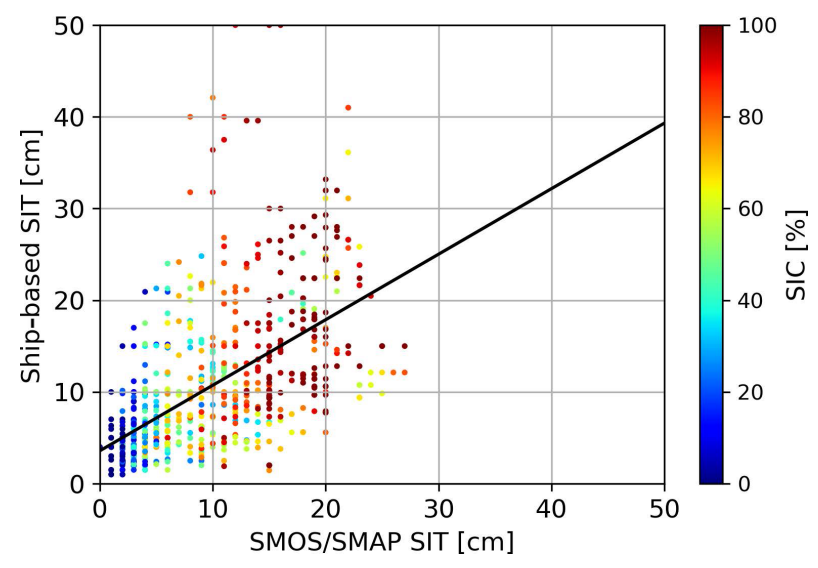

Figure 11. Comparison of ASPeCT-based ice thicknesses observations by R/V Sikuliaq and the SMOS-SMAP retrieval. Ice concentration from the ASI product for the corresponding ice thickness observation is color coded. The black line represents the linear regression of the two datasets.

not be higher than $30 \mathrm{~cm}$ (see Fig. 7). We can see that there is high covariance between the SIC and the SIT, with most low thicknesses appearing in areas with low SIC. The outliers at high SIT are probably caused by local effects, e.g., small pieces of very thick ice close to the ship, while in a larger area of SMOS-SMAP footprints on the order of $20 \mathrm{~km}$ radius, thin ice is dominant. The fact that most of the area was covered by thin ice makes it quite likely that larger area averages yield thinner ice compared to the local observations.

The comparison of ship-based observations with satellitebased observations is problematic as the scale of the observations differs by a large amount. Satellite footprint sizes from SMOS and SMAP are on an order of $20 \mathrm{~km}$ radius, while the observations based on the ASPeCT protocol are very local, with a $1 \mathrm{~km}$ radius. With a straight route of the ship-based ice observations through a SMOS-SMAP satellite footprint, only about $6 \%$ of the area is covered. Therefore this comparison heavily relies on an assumption of the consistency of ice conditions, i.e., high spatial autocorrelation of ice thickness. Taking these differences into account, the comparison actually shows quite a promising agreement between the two datasets.

In Sect. 4.2 we showed that the SIT difference between the old and the new combined retrieval is relatively small. Since this current combined retrieval is based on the empirical (Huntemann et al., 2014) retrieval and training data, using an adaptation to the SMAP incidence angle, changing the RFI filtering methods and using a combination of two sensors, the comparisons and validation of the original product are still valid. For example, a validation study for SMOS SIT data, which also includes the Huntemann et al. (2014) dataset, was done in March 2014 in the Barents Sea (Kaleschke et al., 2016). Measurements included an airborne laser scanner and radiometer, and both airborne and ship- based electromagnetic induction (EM) systems. In that comparison the SMOS ice thickness data are too thin $(-20 \mathrm{~cm})$ compared to the airborne measurements, opposite to what is found here in the comparison to the ship-based data. A good correlation of approximately 0.7 , however, was found between the airborne measurements using the SMOS SIT product. On the other hand, no correlation was found between the ship-based EM observed thickness and the SMOS product, while in our comparison with the ship observations based on the ASPeCT protocol, we find a significant correlation of 0.58 .

\section{Conclusions}

The existing retrieval for thickness of thin sea ice (Huntemann et al., 2014) from the L-band sensor SMOS (launched 2009) has been adapted to SMAP (launched 2015) by (i) modifying the SMOS retrieval to use $40^{\circ}$ incidence angle instead of the average in the range 40 to $50^{\circ}$ and (ii) establishing a linear regression between the SMOS and SMAP TBs at a $40^{\circ}$ incidence angle.

To derive the SMOS TB at a $40^{\circ}$ incidence angle required for the first step, an analytical function is fitted to the incidence-angle-dependent TBs. SMAP top-of-theatmosphere data and the SMOS data fitted to the same incidence angle yield a small TB RMSD between the two datasets for both polarizations of 2.7 and $2.81 \mathrm{~K}$ for $\mathrm{TB}_{\mathrm{h}}$ and $\mathrm{TB}_{\mathrm{v}}$, respectively. This is an improvement compared to previous attempts (Huntemann et al., 2016) for which the RMSD for both polarizations was over $4 \mathrm{~K}$. Moreover the SMOS-based ice thickness retrieval has been adjusted to the new SMOS data version 6.20. The new algorithm contains a new RFI filtering routine exploiting the dependence of the TBs on the incidence angle. This method improved coverage of previously RFI-affected areas. Although the TB datasets of the two sensors are processed differently, the overall resulting thicknesses are similar, with SMOS TBs having smaller variability at lower thicknesses due to the iterative observations' removal operation. The comparison with in situ data shows a good agreement between the combined product and the ship observations.

Concluding, the benefit of SMAP for retrieval of thickness of thin sea ice is twofold: first, the combined product has a better spatial and temporal coverage that can allow insights in future studies, even on a sub-daily scale. The overall increase in spatial coverage is $6 \%$, although most of this is found in the lower latitudes, where the existence of sea ice is minimal. Second, SIT can be retrieved from any of the two sensors alone with similar accuracy, making the production chain more stable in the case of malfunction of one of the two sensors. The algorithm and processing introduced in this paper can be seen as an extension of the method presented in Huntemann et al. (2014) because both methods yield similar values for the retrieved SIT. Therefore, the comparisons done 
in Huntemann et al. (2014) can be used as an additional assessment of the quality of the product presented in this paper.

Maps of thin ice thickness for the winter season in the Arctic and Antarctic are processed on a daily basis and are available at https://www.seaice.uni-bremen.de/start/ (last access: 21 January 2019). In an era when the Arctic melting season and area of first-year ice are increasing, the areas covered by thin ice are also increasing. The new merged SMOS-SMAP ice thickness dataset is consistent with previous SMOS-only based ice thickness retrievals and will allow the thin sea ice thickness record to be extended in the future.

Data availability. The SMOS-SMAP, SMOS and SMAP SIT data are available at https://seaice.uni-bremen.de/start/ (last access: 21 January 2019). This is a service that provides daily data.

Author contributions. CP wrote the paper and all co-authors contributed to the discussion and interpretation of the results. GS and $\mathrm{GH}$ provided the general structure of the paper. $\mathrm{MH}$ wrote fitting routine code and provided technical assistance.

Competing interests. The authors declare that they have no conflict of interest.

Acknowledgements. We gratefully acknowledge the support from the Transregional Collaborative Research Center (TR 172). "ArctiC Amplification: Climate Relevant Atmospheric and SurfaCe Processes, and Feedback mechanisms (AC) ${ }^{3}$ " funded by the German Research Foundation (DFG, Deutsche Forschungsgemeinschaft) and by the EU Horizon 2020 INTAROS (Integrated Arctic Observing System).

The article processing charges for this open-access publication were covered by the University of Bremen.

Edited by: Ted Maksym

Reviewed by: three anonymous referees

\section{References}

Andersen, S., Tonboe, R., Kaleschke, L., Heygster, G., and Pedersen, L. T.: Intercomparison of passive microwave sea ice concentration retrievals over the high-concentration Arctic sea ice, J. Geophys. Res.-Oceans, 112, C08004, https://doi.org/10.1029/2006JC003543, 2007.

Bilello, M. A.: Formation, growth, and decay of sea-ice in the Canadian Arctic Archipelago, Arctic, 14, 2-24, 1961.

Corbella, I., Duffo, N., Vall-llossera, M., Camps, A., and Torres, F.: The visibility function in interferometric aperture synthesis radiometry, IEEE Trans. Geosci. Remote Sens., 42, 1677-1682, 2004.

Corbella, I., Torres, F., Camps, A., Colliander, A., Martín-Neira, M., Ribo, S., Rautiainen, K., Duffo, N., and Vall-llossera, M.: MI-
RAS end-to-end calibration: application to SMOS L1 processor, IEEE Trans. Geosci. Remote Sens., 43, 1126-1134, 2005.

Corbella, I., Durán, I., Wu, L., Torres, F., Duffo, N., Khazâal, A., and Martín-Neira, M.: Impact of Correlator Efficiency Errors on SMOS Land-Sea Contamination, IEEE Geosci. Remote Sens. Lett., 12, 1813-1817, 2015.

Entekhabi, D., Njoku, E. G., O’Neill, P. E., Kellogg, K. H., Crow, W. T., Edelstein, W. N., Entin, J. K., Goodman, S. D., Jackson, T. J., Johnson, J., Kimball, J., Piepmeier, J. R., Koster, R. D., Martin, N., McDonald, K. C., Moghaddam, M., Moran, S., Reichle, R., Shi, J. C., Spencer, M. W., Thurman, S. W., Tsang, L., and Zyl, J. V.: The Soil Moisture Active Passive (SMAP) Mission, Proc. IEEE, 98, 704-716, 2010.

Entekhabi, D., Yueh, S., O’Neill, P., Kellogg, K., Allen, A., Bindlish, R., Brown, M., Chan, S., Colliander, A., Crow, W. T., Das, N., De Lannoy, G., Dunbar, R. S., Edelstein, W. N., Entin, J. K., Escobar, V., Goodman, S. D., Jackson, T. J., Jai, B., Johnson, J., Kim, E., Kim, S., Kimball, J., Koster, R. D., Leonon, A., McDonald, K. C., Moghaddam, M., Mohammed, P., Moran, S., Njoku, E. G., Piepmeier, J. R., Reichle, R., Rogez, F., Shi, J. C., Spencer, M. W., Thurman, S. W., Tsang, L., Van Zyl, J., Weiss, B., and West, R.: SMAP handbook, Tech. rep., available at: https://smap.jpl.nasa.gov/files/smap2/SMAP Handbook_FINAL_1_JULY_2014_Web.pdf (last access: 21 January 2019), 2014.

Font, J., Camps, A., Borges, A., Martin-Neira, M., Boutin, J., Reul, N., Kerr, Y. H., Hahne, A., and Mecklenburg, S.: SMOS: The Challenging Sea Surface Salinity Measurement From Space, Proc. IEEE, 98, 649-665, 2010.

Häkkinen, S.: A constitutive law for sea ice and some applications, Math. Modell., 9, 81-90, 1987.

Heygster, G., Huntemann, M., Ivanova, N., Saldo, R., and Pedersen, L. T.: Response of passive microwave sea ice concentration algorithms to thin ice, in: 2014 IEEE Geoscience and Remote Sensing Symposium, Quebec City, Canada, 13-18 July 2014, 3618-3621, 2014.

Holland, M. M., Serreze, M. C., and Stroeve, J.: The sea ice mass budget of the Arctic and its future change as simulated by coupled climate models, Clim. Dynam., 34, 185-200, 2010.

Huntemann, M. and Heygster, G.: A New Method to Filter Out Radio-Frequency Interference (RFI) from SMOS Level 1C Data for Sea Ice Applications, in: Towards an Interdisciplinary Approach in Earth System Science, edited by: Lohmann, G., Meggers, H., Unnithan, V., Wolf-Gladrow, D., Notholt, J., and Bracher, A., 91-98, Springer International Publishing Switzerland, 2015.

Huntemann, M., Heygster, G., Kaleschke, L., Krumpen, T., Mäkynen, M., and Drusch, M.: Empirical sea ice thickness retrieval during the freeze-up period from SMOS high incident angle observations, The Cryosphere, 8, 439-451, https://doi.org/10.5194/tc-8-439-2014, 2014.

Huntemann, M., Patilea, C., and Heygster, G.: Thickness of thin sea ice retrieved from SMOS and SMAP, in: Proceedings of 2016 IEEE International Geoscience and Remote Sensing Symposium (IGARSS), Beijing, China, 10-15 July 2016, 5248-5251, 2016.

Indra Sistemas S.A.: SMOS Level 1 and Auxiliary Data Products Specifications, Product Document, available at: https://earth.esa.int/documents/10174/1854583/SMOS_L1_ 
Aux_Data_Product_Specification (last access: 28 March 2018), Madrid, 2014.

Ivanova, N., Pedersen, L. T., Tonboe, R. T., Kern, S., Heygster, G., Lavergne, T., Sørensen, A., Saldo, R., Dybkjær, G., Brucker, L., and Shokr, M.: Inter-comparison and evaluation of sea ice algorithms: towards further identification of challenges and optimal approach using passive microwave observations, The Cryosphere, 9, 1797-1817, https://doi.org/10.5194/tc9-1797-2015, 2015.

Kaleschke, L., Maaß, N., Haas, C., Hendricks, S., Heygster, G., and Tonboe, R. T.: A sea-ice thickness retrieval model for $1.4 \mathrm{GHz}$ radiometry and application to airborne measurements over low salinity sea-ice, The Cryosphere, 4, 583-592, https://doi.org/10.5194/tc-4-583-2010, 2010.

Kaleschke, L., Tian-Kunze, X., Maaß, N., Mäkynen, M., and Drusch, M.: Sea ice thickness retrieval from SMOS brightness temperatures during the Arctic freeze-up period, Geophys. Res. Lett., 39, 105501, https://doi.org/10.1029/2012GL050916, 2012.

Kaleschke, L., Tian-Kunze, X., Maaß, N., Heygster, G., Huntemann, M., Wang, H., Hendricks, S., Krumpen, T., Tonboe, R., Mäkynen, M., and Haas, C.: STSE-SMOS Sea Ice Retrieval Study (SMOSIce), Technical Report, available at: https://icdc.cen.uni-hamburg.de/fileadmin/user_upload/icdc_ Dokumente/SMOS_SIT/SMOSICE_FinalReport_2013.pdf (last access: 31 March 2018), ESA ESTEC, 2013.

Kaleschke, L., Tian-Kunze, X., Maaß, N., Beitsch, A., Wernecke, A., Miernecki, M., Müller, G., Fock, B. H., Gierisch, A. M., Schlünzen, K. H., Pohlmann, T., Dobrynin, M., Hendricks, S., Asseng, J., Gerdes, R., Jochmann, P., Reimer, N., Holfort, J., Melsheimer, C., Heygster, G., Spreen, G., Gerland, S., King, J., Skou, N., Søbjærg, S. S., Haas, C., Richter, F., and Casal, T.: SMOS sea ice product: Operational application and validation in the Barents Sea marginal ice zone, Remote Sensing of Environment, 180, 264-273, special Issue: ESA's Soil Moisture and Ocean Salinity Mission - Achievements and Applications, 2016.

Kerr, Y. H., Waldteufel, P., Wigneron, J. P., Martinuzzi, J., Font, J., and Berger, M.: Soil moisture retrieval from space: the Soil Moisture and Ocean Salinity (SMOS) mission, IEEE Trans. Geosci. Remote Sens., 39, 1729-1735, 2001.

Kerr, Y. H., Waldteufel, P., Richaume, P., Wigneron, J. P., Ferrazzoli, P., Mahmoodi, A., Bitar, A. A., Cabot, F., Gruhier, C., Juglea, S. E., Leroux, D., Mialon, A., and Delwart, S.: The SMOS Soil Moisture Retrieval Algorithm, IEEE Trans. Geosci. Remote Sens., 50, 1384-1403, 2012.

Lannoy, G. J. M. D., Reichle, R. H., Peng, J., Kerr, Y., Castro, R., Kim, E. J., and Liu, Q.: Converting Between SMOS and SMAP Level-1 Brightness Temperature Observations Over Nonfrozen Land, IEEE Geosci. Remote Sens. Lett., 12, 1908-1912, 2015.

Li, Y., Li, Q., and Lu, H.: Land Contamination Analysis of SMOS Brightness Temperature Error Near Coastal Areas, IEEE Geosci. Remote Sens. Lett., 14, 587-591, 2017.

Martín-Neira, M., Oliva, R., Corbella, I., Torres, F., Duffo, N., Durán, I., Kainulainen, J., Closa, J., Zurita, A., Cabot, F., Khazaal, A., Anterrieu, E., Barbosa, J., Lopes, G., Tenerelli, J., DíezGarcía, R., Fauste, J., Martín-Porqueras, F., González-Gambau, V., Turiel, A., Delwart, S., Crapolicchio, R., and Suess, M.: SMOS instrument performance and calibration after six years in orbit, Remote Sens. Environ., 180, 19-39, special Issue: ESA's
Soil Moisture and Ocean Salinity Mission - Achievements and Applications, 2016.

Maykut, G. A.: Energy exchange over young sea ice in the central Arctic, J. Geophys. Res.-Oceans, 83, 3646-3658, 1978.

McMullan, K. D., Brown, M. A., Martín-Neira, M., Rits, W., Ekholm, S., Marti, J., and Lemanczyk, J.: SMOS: The Payload, IEEE Trans. Geosci. Remote Sens., 46, 594-605, 2008.

Mecklenburg, S., Drusch, M., Kerr, Y. H., Font, J., Martin-Neira, M., Delwart, S., Buenadicha, G., Reul, N., Daganzo-Eusebio, E., Oliva, R., and Crapolicchio, R.: ESA's Soil Moisture and Ocean Salinity Mission: Mission Performance and Operations, IEEE Trans. Geosci. Remote Sens., 50, 1354-1366, 2012.

Mills, P. and Heygster, G.: Sea Ice Emissivity Modeling at L-Band and Application to 2007 Pol-Ice Campaign Field Data, IEEE Trans. Geosci. Remote Sens., 49, 612-627, 2011.

Mohammed, P. N., Aksoy, M., Piepmeier, J. R., Johnson, J. T., and Bringer, A.: SMAP L-Band Microwave Radiometer: RFI Mitigation Prelaunch Analysis and First Year On-Orbit Observations, IEEE Trans. Geosci. Remote Sens., 54, 6035-6047, 2016.

Moritz, R. E., Bitz, C. M., and Steig, E. J.: Dynamics of Recent Climate Change in the Arctic, Science, 297, 1497-1502, 2002.

Oliva, R., Daganzo, E., Kerr, Y. H., Mecklenburg, S., Nieto, S., Richaume, P., and Gruhier, C.: SMOS Radio Frequency Interference Scenario: Status and Actions Taken to Improve the RFI Environment in the 1400-1427-MHz Passive Band, IEEE Trans. Geosci. Remote Sens., 50, 1427-1439, 2012.

Perovich, D. K., Grenfell, T. C., Light, B., and Hobbs, P. V.: Seasonal evolution of the albedo of multiyear Arctic sea ice, J. Geophys. Res.-Oceans, 107, SHE20-1-SHE20-13, 2012.

Sahr, K., White, D., and Kimerling, A. J.: Geodesic Discrete Global Grid Systems, Cartography and Geographic Information Science, Cartogr. Geogr. Inform. Sci., 30, 121-134, 2003.

Schmitt, A. U. and Kaleschke, L.: A Consistent Combination of Brightness Temperatures from SMOS and SMAP over Polar Oceans for Sea Ice Applications, Remote Sens., 10, 553, https://doi.org/10.3390/rs10040553, 2018.

Shokr, M. and Sinha, N.: Sea ice: Physics and Remote Sensing, John Wiley \& Sons, 2015.

Skou, N. and Hoffman-Bang, D.: L-band radiometers measuring salinity from space: atmospheric propagation effects, IEEE Trans. Geosci. Remote Sens., 43, 2210-2217, 2005.

SMOS Calibration team and Expert Support Laboratory Level 1: SMOS L1OPv620 release note, Release Note, ESA, available at: https://earth.esa.int/documents/10174/1854503/SMOS_ L1OPv620_release_note (last access: 9 February 2018), 2015.

Spreen, G., Kaleschke, L., and Heygster, G.: Sea ice remote sensing using AMSR-E 89-GHz channels, J. Geophys. Res.-Oceans, 113, C2, https://doi.org/10.1029/2005JC003384, 2008.

Stroeve, J., Holland, M. M., Meier, W., Scambos, T., and Serreze, M.: Arctic sea ice decline: Faster than forecast, Geophys. Res. Lett., 34, 9, https://doi.org/10.1029/2005JC003384, 2007.

Tian-Kunze, X., Kaleschke, L., Maaß, N., Mäkynen, M., Serra, N., Drusch, M., and Krumpen, T.: SMOS-derived thin sea ice thickness: algorithm baseline, product specifications and initial verification, The Cryosphere, 8, 997-1018, https://doi.org/10.5194/tc8-997-2014, 2014.

Worby, A. P. and Ackley, S. F.: Antarctic research yields circumpolar sea ice thickness data, Eos, Trans. Am. Geophys. Union, 81, 181-185, 2000. 
Yu, Y., Rothrock, D. A., and Zhang, J.: Thin ice impacts on surface salt flux and ice strength: Inferences from advanced very high resolution radiometer, J. Geophys. Res.-Oceans, 106, 1397513988, 2001.

Zhao, T. J., Shi, J. C., Bindlish, R., Jackson, T. J., Kerr, Y., Cosh, M. H., Cui, Q., Li, Y. Q., Xiong, C., and Che, T.: Refinement of SMOS multiangular brightness temperature toward soil moisture retrieval and its analysis over reference targets, IEEE J. Selected Top. Appl. Earth Observ. Remote Sens., 8, 589-603, 2015.
Zine, S., Boutin, J., Font, J., Reul, N., Waldteufel, P., Gabarro, C. Tenerelli, J., Petitcolin, F., Talone, J. V. M., and Delwart, S.: Overview of the SMOS sea surface salinity prototype processor, IEEE-Trans. Geosci. Remote Sens., 46, 621-645, 2008. 